\title{
Variability in Spent Fuel Inventory Data
}

\author{
Kristina Yancey1a, Pavel V. Tsvetkov2a \\ a Texas A\&M University, 3133 TAMU, College Station, TX 77843-3133, USA \\ ${ }^{1}$ Corresponding Author: kristina.yancey@gmail.com, (979)492-4082 \\ 2tsvetkov@tamu.edu
}

Key Words: applicability range; nuclear power; spent fuel; nuclide; actinides; fission products

\begin{abstract}
A new methodology has been developed to assess how representative a collection of nuclide mass estimates is of real-world spent fuel. The analysis is approached as an "applicability range" evaluation, which quantifies the fraction of the historical population that is represented by one mass estimate. The new methodology is applied to a database containing spent fuel inventory estimates for operating U.S. reactors and uses historical assembly designs as a reference. The evaluation consists of two major steps: the implementation of a sampling and randomization scheme and the calculation of the applicability range scores. The mass estimates are assigned scores for each of the assembly designs they should represent, and the scores are averaged together to find overall applicability range scores for the database estimates. The results showed that the estimates for newer, PWR assembly classes had much higher scores than estimates for older or BWR assembly classes. The applicability range methodology can be extended beyond the database analyzed in the present work to any study that needs to use one value to represent a population with broad variations and limited knowledge of the underlying distributions.
\end{abstract}




\section{Introduction}

This paper presents a new methodology to quantify how representative an estimate is of a variable based on the known historical variation of its input factors. The method is applied to the analysis of the Spent Fuel Database (SFD), which was created for advanced fuel cycle and waste management studies (Yancey and Tsvetkov, 2014).The database was built using publicly available information to model individual spent fuel assemblies in ORIGEN-ARP (Gauld et al., 2009) and contains estimates of the nuclide inventories in those assemblies. The new method was developed as a way to understand some of the uncertainty of the mass estimates in the SFD.

\subsection{Spent Fuel Database}

The models used to create the SFD are generalized versions of their real-life counterparts. The database covers the 103 United States (U.S.) nuclear reactors that were operating in January 2012. The model for each reactor used available information about power levels, capacity factors, and more to generate mass estimates for 98 nuclides, including actinides and 20 fission products, on a per assembly basis. The models included certain assumptions that, together with the variability in the input data, could distort the estimates in the database. A previous paper discusses the broader implications of the assumptions that were made (Yancey and Tsvetkov, 2014). This paper explores two specific assumptions that could affect how many real-world assemblies the SFD estimates would be able to represent: enrichment and initial uranium content.

In 2012, a paper was released by Oak Ridge National Laboratory (ORNL) reporting the results of a technical review conducted by the U.S. Department of Energy's Office of Fuel Cycle Technologies (Wagner et al., 2012). This report greatly augmented publicly available information about spent fuel. For the models used to create the SFD, the ${ }^{235} \mathrm{U}$ enrichment was assumed to be 4.0 wt.\%, and the initial uranium content was chosen for each reactor based on context clues in (EIA, 1995). The ORNL report included tabulated information about these two input variables that 
facilitated the development of the new method presented here. While it did not give the exact enrichment and initial uranium content used by each reactor over the course of its lifetime, the report did present average values along with maximum and, in the case of enrichment, minimum values for historical assembly designs used by industry up until 2004. Fig. 1 was compiled based on the average enrichment values given in the ORNL report. The histogram shows the variation in enrichment from 1.5 to 5.0 wt.\% enrichment in $0.05 \%$ increments. As shown in Fig. 1, the spread around the assumed value of $4.0 \mathrm{wt} . \%$ is quite large, with $92.8 \%$ of the assemblies falling below that value.

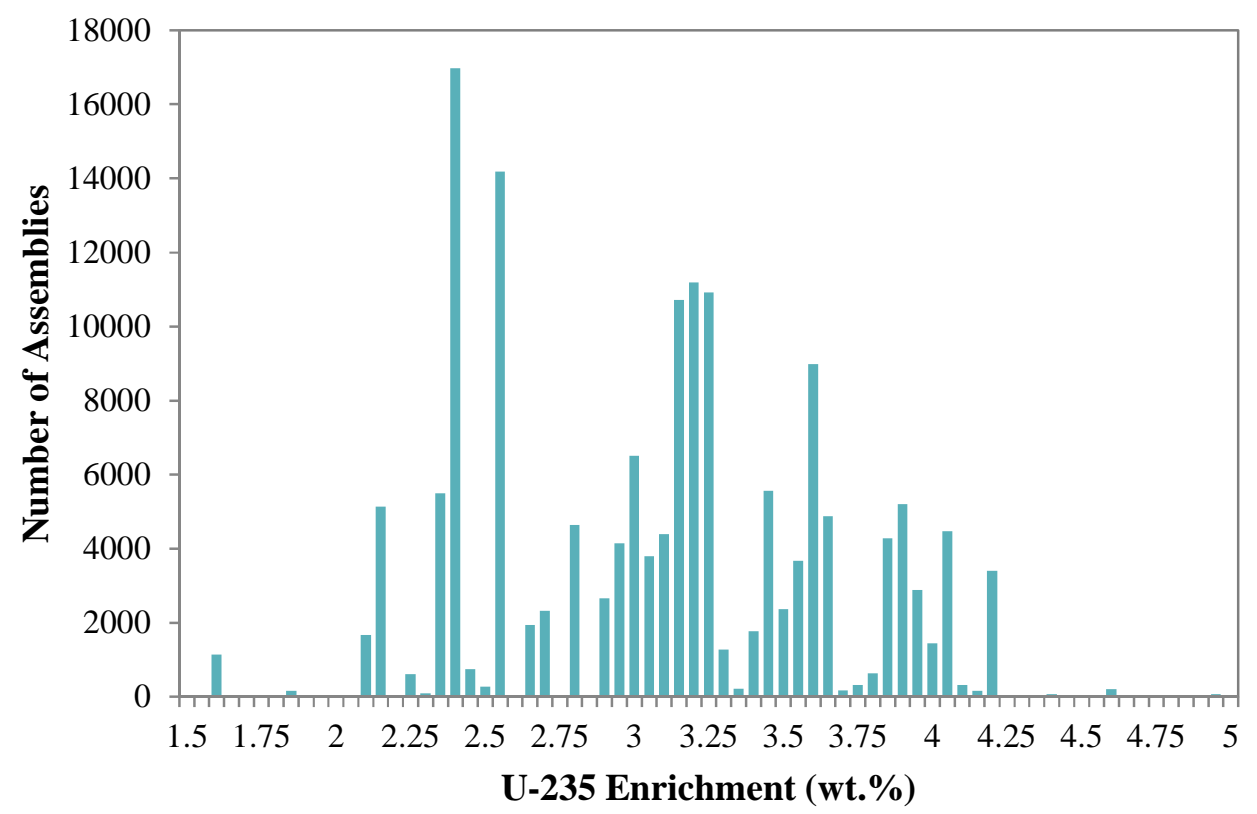

Fig. 1. The variation of ${ }^{235} \mathrm{U}$ enrichment in fresh fuel assemblies used in U.S. reactors up until 2004.

Expanding on the data presented in Fig. 1, Fig. 2 shows that even if the historical average enrichment level was chosen instead of $4.0 \mathrm{wt} . \%$, one standard enrichment level poorly represents the population. Fig. 2 was created using JMP ${ }^{1}$ (2012) and shows that a normal distribution does not fit the data. Using the KSL "goodness of fit" test, the normal distribution was ruled out as a sufficient 
model at a significance level of $95 \%$, with a p-value of 0.001 . These figures suggest that variation in enrichment must have some impact on the database. No single enrichment is a good representation of the levels used in the past.

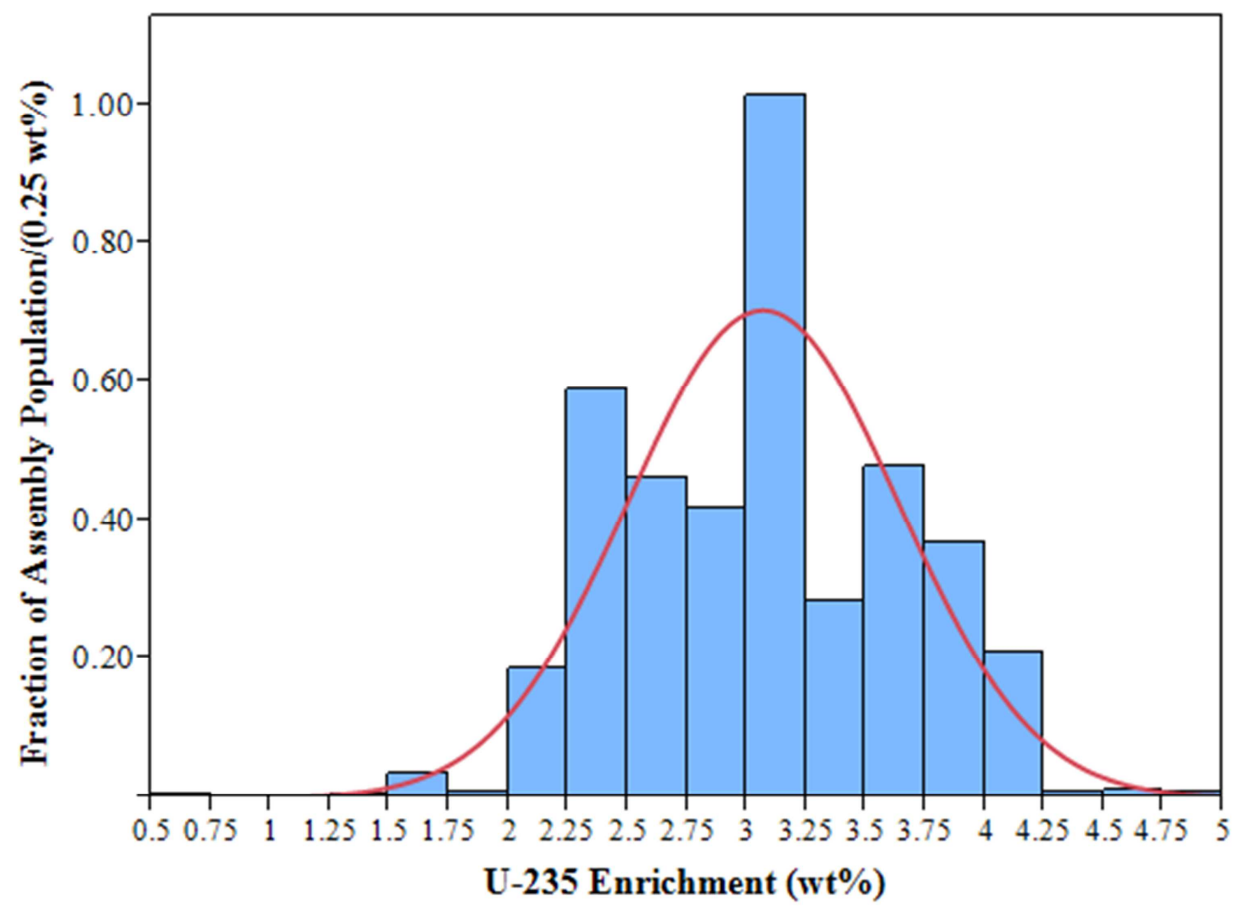

Fig. 2. ${ }^{235 U}$ enrichment levels used in U.S. reactors up until 2004 with a Normal(3.06584,0.56754) continuous fit overlay.

Burnup effects were neglected in this study even though the ORNL report also listed average and maximum values for this factor. It is recognized that burnup will significantly affect the accuracy of the database mass estimates, but the methodology used to generate the ORIGEN-ARP models did not accommodate a simple perturbation in this respect. It was assumed that each assembly went through three 1.5 year cycles in the reactor and that the cycles were separated by refueling outages at $0 \%$ power. The length of an outage was determined by the capacity factor for an individual reactor in a given year. With this setup, changing the burnup would affect more than 
one parameter. For each sample run, it would need to be decided if the burnup should only perturb the length of each cycle, or if it would be more accurate to reduce the number of cycles to two. While the choice may not significantly affect the dominant fissile nuclides, it would affect the higher actinides, such as the concentration of ${ }^{242} \mathrm{Cm}$. To evaluate the SFD required over 54,000 new runs, so incorporating these additional complications into the analysis was beyond the scope of this study. In a formal uncertainty quantification, burnup must be considered.

While the ORNL report did not connect exact values to individual reactor units, the assembly design information can be connected to specific assembly classes. These classes are listed in Table I, which is reprinted here for clarity (Yancey and Tsvetkov, 2014). Table I presents average power histories for each assembly class, calculated using the collected information from all of the units belonging to a certain class (EIA, 1995; NRC, 2011a, c). The assembly classes are abbreviated company names followed by a multiplication factor, denoting the size of the assembly. Here, "BW" stands for Babcock \& Wilcox, "CE” stands for Combustion Engineering, "GE” stands for General Electric, and "W" stands for Westinghouse. The assembly designs listed in the ORNL report were connected to each class through cross-referencing (EIA, 1995). To emphasize the distinction between assembly design and assembly class, "assembly class" refers to the structure of a reactor, while "assembly design" refers specifically to the type of assembly going into the reactor. A reactor's assembly class cannot change, while the assembly design often changes to accommodate higher burnups and other technological improvements. 
Table I. Reactor classification groups and averaged power histories over the units belonging to the assembly design class.

\begin{tabular}{|c|c|c|c|c|c|c|}
\hline $\begin{array}{l}\text { Design } \\
\text { Class }\end{array}$ & $\begin{array}{l}\text { Number } \\
\text { of Units } \\
\text { in Class }\end{array}$ & $\begin{array}{c}\text { First } \\
\text { Month of } \\
\text { Operation }\end{array}$ & $\begin{array}{l}\text { Initial } \\
\text { Power } \\
\text { (MWth) }\end{array}$ & $\begin{array}{l}\text { Month of } \\
\text { Uprate }\end{array}$ & $\begin{array}{c}\text { Final } \\
\text { Power } \\
\text { (MWth) }\end{array}$ & $\begin{array}{l}\text { Number of } \\
\text { Assemblies }\end{array}$ \\
\hline \multicolumn{7}{|c|}{ PWR } \\
\hline BW $15 \times 15$ & 6 & May 1975 & 2609 & -- & 2610 & 177 \\
\hline CE $14 \times 14$ & 4 & May 1976 & 2560 & Apr. 1989 & 2719 & 217 \\
\hline CE $16 \times 16$ & 4 & June 1983 & 3246 & July 2002 & 3405 & 217 \\
\hline $\begin{array}{c}\text { CE } 16 \times 16 \\
\text { Sys } 80\end{array}$ & 4 & Apr. 1985 & 3554 & Dec. 2000 & 3749 & 241 \\
\hline W 14x14 & 6 & Dec. 1972 & 1488 & Feb. 2007 & 1664 & 121 \\
\hline W 15x15 & 8 & Nov. 1973 & 2671 & Aug. 2000 & 2799 & 157 \\
\hline W 17x17 & 32 & Jan. 1985 & 3227 & Nov. 2000 & 3355 & 193 \\
\hline \multicolumn{7}{|c|}{ BWR } \\
\hline GE $7 x 7$ & 8 & Aug. 1971 & 2191 & Aug. 2001 & 2426.4 & 724 \\
\hline GE $8 \times 8^{*}$ & 27 & Mar. 1981 & 2980 & Dec. 2003 & 3263 & 764 \\
\hline
\end{tabular}

*This class also has an additional uprate between start-up and the final uprate. This average middle uprate occurred in June 1992, increasing power to 3146 MWth.

\subsection{Applicability Range}

A traditional sensitivity analysis could not be performed on the mass estimates because the sample size within the database was too small, and the choices of enrichment and of initial uranium content by industry were not random. The levels for both were decided based on what was best commercially for each reactor according to specific utility practices. Therefore, the distributions of the enrichment levels and the initial uranium content used over the past forty-some years are not normal. Within the field of statistics, certain analysis methods are available to understand non- 
normal distributions, but they are beyond the scope of this work. Instead, a simple methodology was developed to assess what will be called the "applicability range" of the database.

For the purpose of this research, the applicability range (AR) is defined as the fraction of assemblies used over a reactor's lifetime that could be represented by the SFD estimates with respect to available historical information, in this case, enrichment and initial uranium content. More generally, it can be defined as the fraction of some set of historical data that is represented by one estimate. The idea of an AR accommodates the uncertainty of given historical values while trying to determine the bias of an estimate. The methodology is developed in the context of the SFD but can be extended to fit other purposes. Any study that seeks one representative value for a parameter might find this idea useful if that parameter has a history of wide variation and a noted lack of access to the complete set of historical data.

The purpose of this article is two-fold: to introduce the idea of an AR and to analyze the SFD using this concept. This paper is split into two main sections. Section 2 describes the methodology used to calculate the AR of an estimate. Section 3 presents the results of the analysis and discusses the implications of those results.

\section{Methodology}

The procedure for calculating the AR starts at the individual reactor level. Accordingly, the methodology will be presented here using the Ginna reactor unit to enable a concrete explanation, but the steps described in this section were performed for all 103 reactors in the SFD. The R. E. Ginna Nuclear Power Plant is located in Ontario, NY, and operates one unit from the W14x14 assembly class (NRC, 2011c). The reactor is rated at $1175 \mathrm{MW}_{\text {th }}$ and has routinely run at a capacity factor over 90\% since 2004 (NRC, 2011b). The W14x14 assembly class has historically used 6 assembly designs, listed in Table 2 . The table presents the enrichment and initial uranium content data listed in the ORNL report and gives the corresponding number of assemblies used for each 
design through 2004. It is unknown which of the designs in Table 2 were used at Ginna or when they were used. Therefore, an AR cannot be calculated solely for Ginna but has to be shared by all of the reactors in the $\mathrm{W} 14 \mathrm{x} 14$ assembly class.

Table 2. Assembly designs historically used in the $\mathrm{W} 14 \mathrm{x} 14$ assembly class with publicly available enrichment and initial uranium content values (Wagner et al., 2012), arranged from lowest to highest average initial $235 \mathrm{U}$ mass.

\begin{tabular}{|c|c|c|c|c|c|c|}
\hline $\begin{array}{c}\text { Assembly } \\
\text { Design }\end{array}$ & $\begin{array}{c}\text { Min. } \\
\text { Enrichment } \\
\text { (wt\%) }\end{array}$ & $\begin{array}{c}\text { Avg. } \\
\text { Enrichment } \\
\text { (wt\%) }\end{array}$ & $\begin{array}{c}\text { Max. } \\
\text { Enrichment } \\
\text { (wt\%) }\end{array}$ & $\begin{array}{c}\text { Avg. Initial } \\
\text { Uranium } \\
\text { Content } \\
\text { (kg/assembly) }\end{array}$ & $\begin{array}{c}\text { Max. Initial } \\
\text { Uranium } \\
\text { Content } \\
\text { (kg/assembly) }\end{array}$ & $\begin{array}{c}\text { No. of } \\
\text { Assemblies } \\
\text { Used thru } \\
\mathbf{2 0 0 4}\end{array}$ \\
\hline W1414W & 2.26 & 3.04 & 3.47 & 393.896 & 403.683 & 603 \\
W1414WL & 2.27 & 3.07 & 3.41 & 399.092 & 405.809 & 1429 \\
W1414ATR & 2.39 & 3.38 & 3.57 & 362.788 & 368.011 & 288 \\
W1414B & 3.22 & 3.22 & 3.22 & 383.157 & 383.157 & 2 \\
W1414A & 0.71 & 3.42 & 4.50 & 378.274 & 406.840 & 1018 \\
W1414W0 & 0.99 & 3.92 & 4.95 & 355.724 & 369.265 & 2108 \\
\hline
\end{tabular}

The historical distributions of the assembly designs range from small to large. The spread even reduces to nothing in some designs, mainly due to the small batch sizes that were manufactured, such as for the W1414B design. This data is presented graphically in Fig. 3. The probability density functions (pdfs) are triangular due to the limited information available-the minimum, maximum, and average values for the factors listed in Table 2. By definition, a pdf integrates to 1.0 from the minimum to the maximum, so the height of each pdf only corresponds to how wide its distribution is. To also emphasize the importance of each design in determining the AR, the number of assemblies per design is overlaid as bar charts in the figure, positioned at their average values. Fig. 3 demonstrates again why it would be difficult for one value to represent all historical variation of a parameter. The averages are spread apart, and their distributions may or 


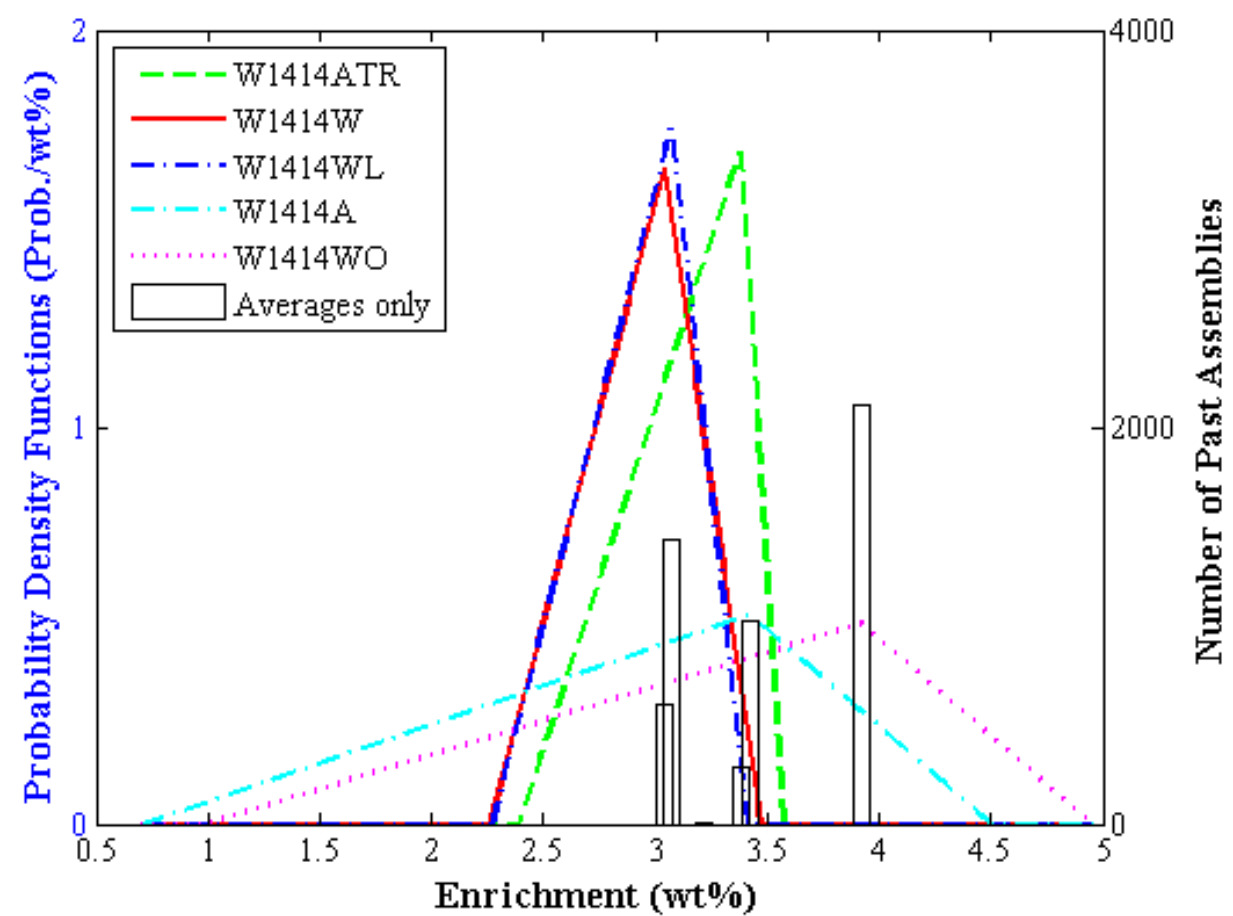

(a)

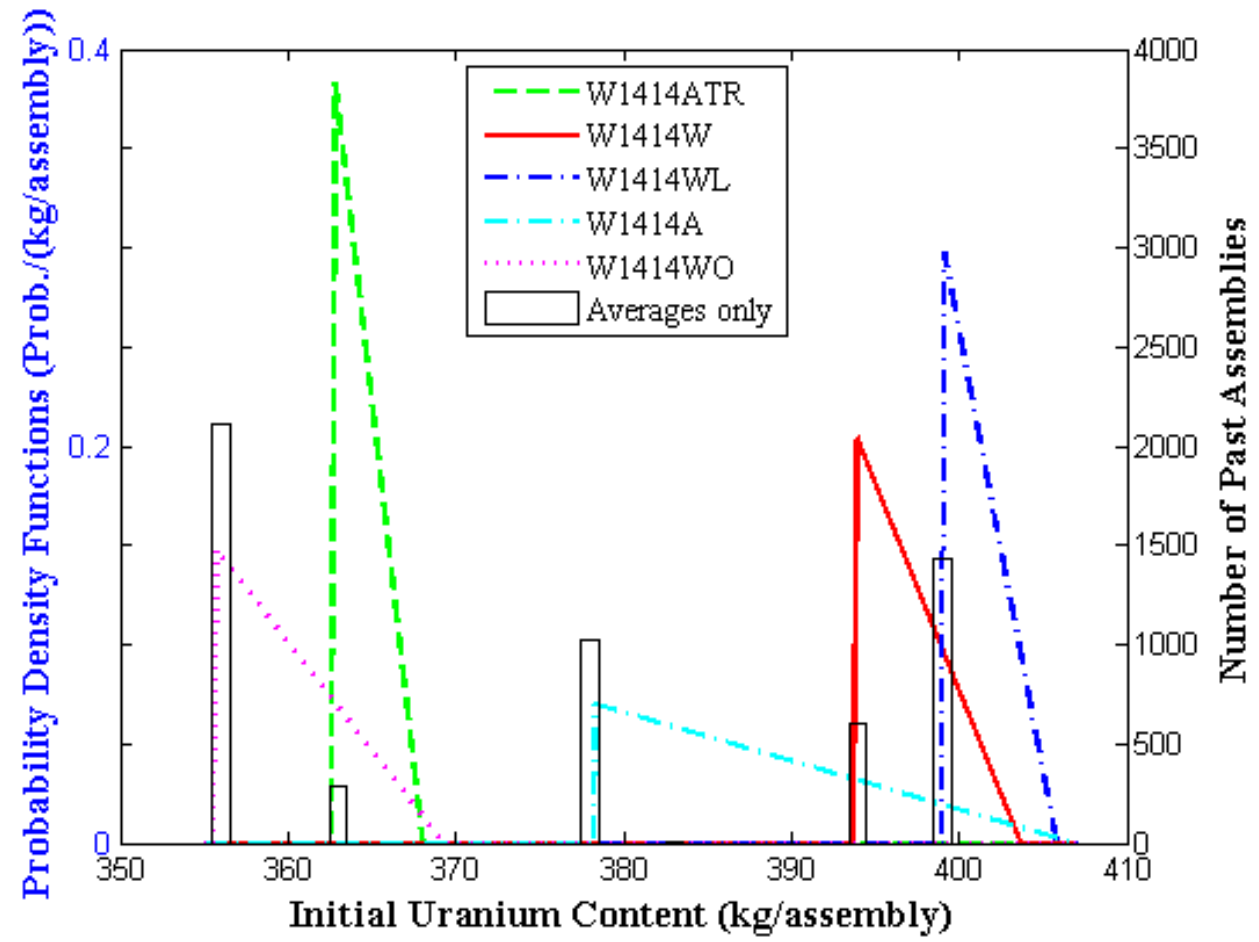

(b)

Fig. 3. Variation in (a) enrichment and (b) initial uranium content within the W14x14 assembly designs. The triangular distributions correspond to the left axis, and the bar chart (averages only) corresponds to the right axis. 
may not overlap each other. At the same time, the plots speak to the possibility of an estimate being able to represent more than one assembly design. The idea of an AR seeks to quantify that effect.

The first step in the AR methodology is to set up a sampling and randomization procedure. The Latin Hypercube Sampling (LHS) method was used based on its ability to efficiently reproduce triangular distributions (Vose, 2000). The LHS method relies on the assumption that the variables are independent (Minasny, 2004). For nuclear reactors, the design choices of enrichment and initial uranium content are correlated, but the relationship is unclear for their variation from individual assembly to assembly. The variation in enrichment is most likely due to static or noise during the enrichment process. The variation in initial uranium content is most likely due to fuel fabrication. Since these are separate steps in the fuel cycle, the variation of the two variables should be independent, but this cannot be confirmed without an extensive statistical evaluation of the fuel cycle. For this study, the fluctuations in the two input variables were assumed to be independent from each other.

The LHS scheme used for this research combined the sequences presented in (Vose, 2000) and (Minasny, 2004). The scheme can be summarized as follows:

1. Determine $n=$ number of iterations to be performed for a particular assembly design.

2. Split the pdf into $n$ intervals of equal probability. Sample from each interval only once.

3. For each interval, generate a random number to find a random probability.

4. Calculate the sample value from the random probability using the inverse cumulative density function.

5. Complete steps 2 through 4 for each of the input variables (enrichment and initial uranium content). 
6. Randomly pair the sample values from input variables.

7. Repeat steps 1 through 6 for each assembly design in the class, generating new random numbers for each design.

8. Repeat steps 1 through 7 for each reactor belonging to the class, generating new random numbers for each reactor.

The first step in the LHS scheme is to determine the number of iterations ( $n$ ) to be performed for a particular assembly design. This will split up the triangular distributions associated with that design into $n$ intervals of equal probability from which the sampling will be taken, as shown in Fig. 4. Without access to an established routine for determining the optimum sample size of a triangular distribution, a decision-making algorithm was created to pick $n$. The first level of the algorithm assigned the value " 1 " to $n$ if there was no variation in either enrichment or initial uranium content. If variation was present, but the total population of the design was smaller than 25 assemblies, then $n$ was assigned to be the same size as the population. If the total population was larger than 25 assemblies, then the square root of the population was calculated. If the square root was smaller than 25, then $n$ was assigned to be 25; but if it was larger, then $n$ was assigned to be the square root, rounded to the closest whole number. In the case of W1414W assembly design shown in Fig. 4, the algorithm assigned a value of 25 to $n$. 

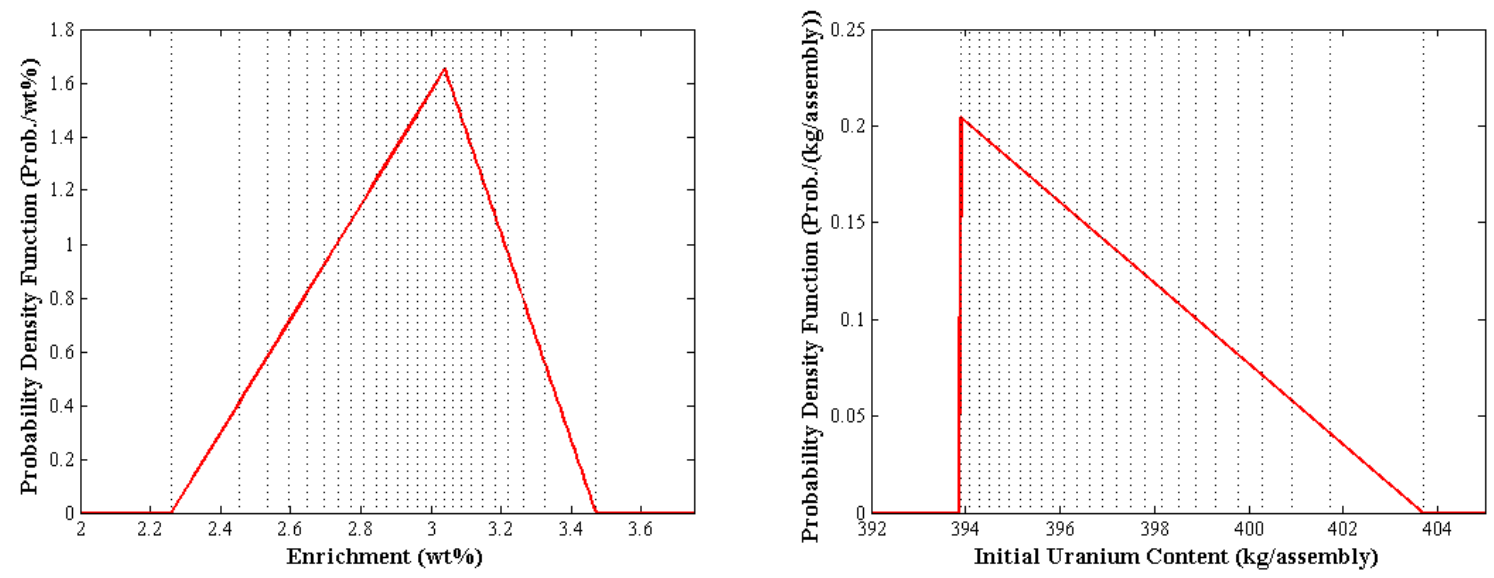

Fig. 4. Probability density functions for the W1414W assembly design, showing 25 equiprobable intervals. Enrichment is shown on the left, and initial uranium content is shown on the right.

After determining the value of $n$, the procedure then goes through each interval once. A random number is generated, which returns a random probability that can be converted into the randomly selected sample value in that interval. The probability is found using Eq. (1), which was adapted from (Minasny, 2004).

$$
y=\left(\frac{1}{n}\right) r_{u}+\left(\frac{i-1}{n}\right)
$$

Here, $y$ is the random probability in interval $i$, and $r_{u}$ is the randomly generated number. The probability is converted to a sample value using Eq. (2) for enrichment or Eq. (3) for initial uranium content. These equations were adapted from the inverse cumulative density functions found in (Kotz and Dorp, 2004).

$F^{-1}(y \mid a, m, b, n)$

$$
\begin{gathered}
=\left\{\begin{array}{c}
a+\sqrt{y(m-a)(b-a)} \text { for } 0 \leq y \leq \frac{m-a}{b-a} \\
b-\sqrt{(1-y)(b-m)(b-a)} \text { for } \frac{m-a}{b-a} \leq y \leq 1
\end{array}\right. \\
F^{-1}(y \mid a, m, b, n)=\{b-(b-m) \sqrt{(1-y)} \text { for } 0 \leq y \leq 1
\end{gathered}
$$


Here, $F^{-1}(y \mid a, m, b, n)$ is the randomly selected sample value, $a$ is the minimum point of the triangular distribution, $b$ is the maximum point of the distribution, and $m$ is the average value of the input variable.

After all of the intervals in both distributions have been assigned values, the enrichment and initial uranium content are randomly paired together. Each pair determines the masses of ${ }^{235} \mathrm{U}$ and ${ }^{238} \mathrm{U}$ for one sample point. Using new random numbers for each pass is important to emphasize the individuality of the assembly designs and of the reactor units. It may not be possible to correlate certain designs to individual reactors, but the randomization strengthens the AR of the assembly class as a whole by spreading out the distributions to better account for the uncertainty inherent in the data. For each reactor unit, the original ORIGEN-ARP models discussed in (Yancey and Tsvetkov, 2014) were modified with the new uranium masses for each sample point. All of the new LHS input files were run, and the output was organized with the help of a FORTRAN program.

The second major step in the methodology is to determine the AR of the SFD mass estimates. The method for calculating this is summarized as follows:

1. Evaluate the SFD estimate against the mass distributions of one assembly design.

a. Score as " 1 " if the estimate is not ruled out.

b. Score as " 0 " if the estimate is ruled out.

2. Combine the scores of the assembly designs to calculate the individual reactor scores.

3. Average the scores of all the reactors in an assembly class to produce an overall score for the SFD estimates in that class. 


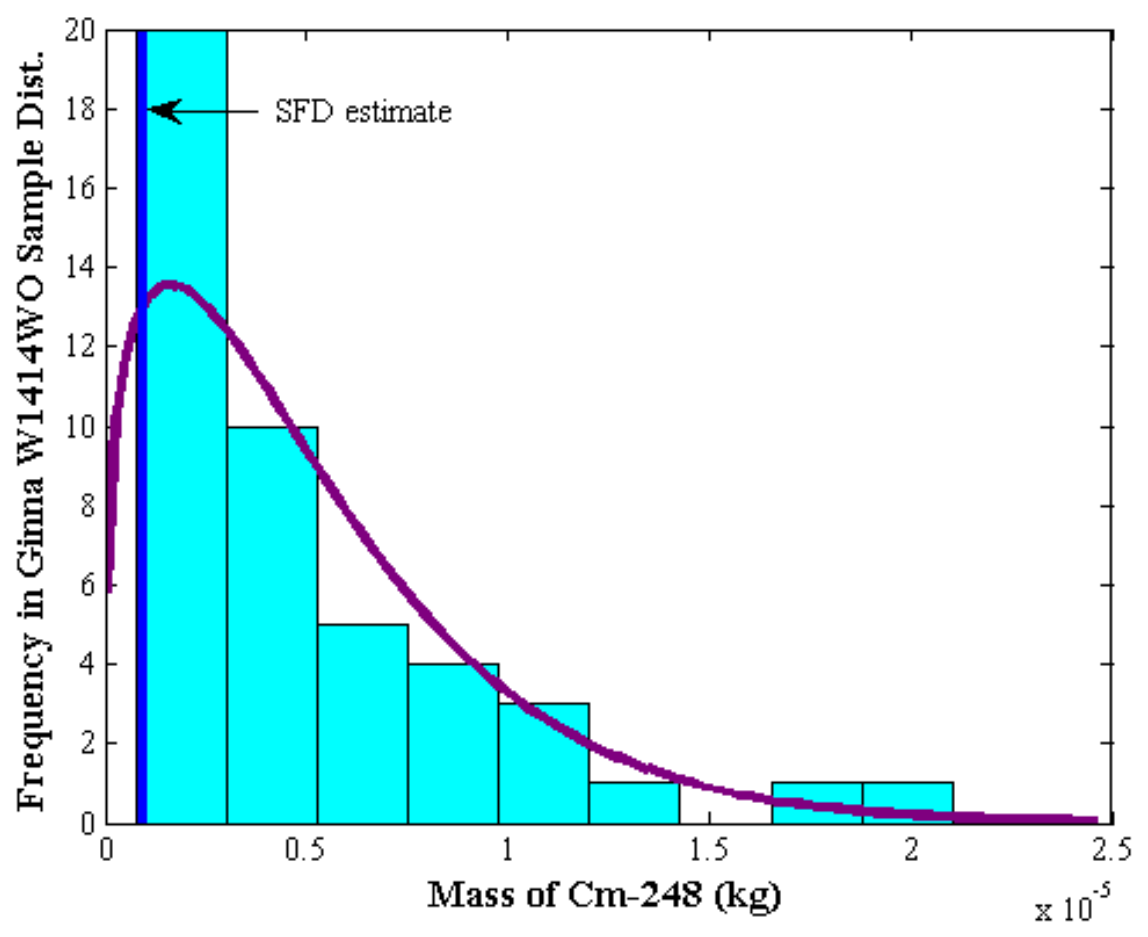

(a)

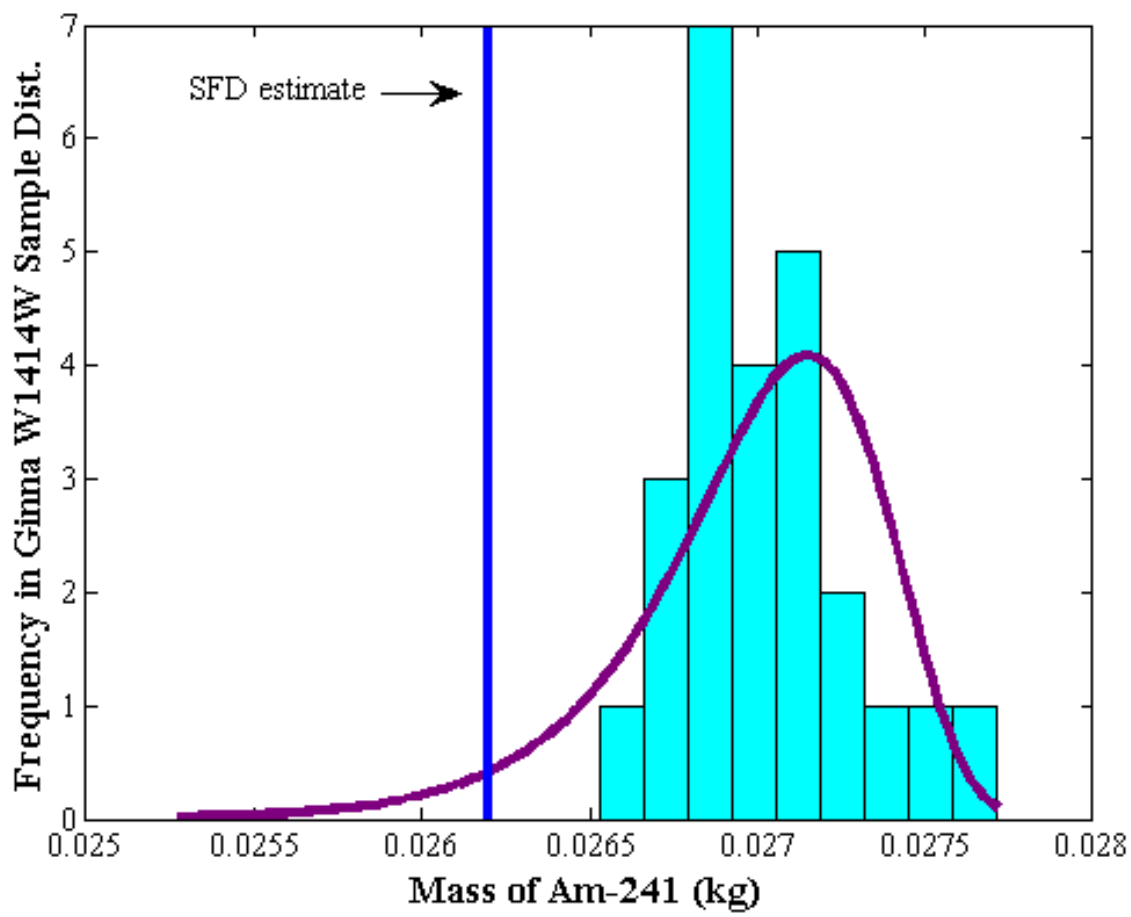

(b)

Fig. 5. Histograms with Weibull overlays for (a) the sample masses of ${ }^{248} \mathrm{Cm}$ in the $\mathrm{W} 1414 \mathrm{WO}$ assembly design and (b) the sample masses of ${ }^{241} \mathrm{Am}$ in the W1414W design, both compared to the respective SFD estimate for the Ginna spent fuel. 
The first step in the calculation features a two-path approach to determine if the SFD estimate could be representative of the assembly design. The first path is available to larger sample sizes with well-formed distributions. For a distribution to qualify, it must have more than 25 sample points and must not be ruled out as a candidate for a Weibull distribution using the chisquare test at a significance level of $95 \%$. The Weibull distribution was chosen because it enforces positive values and is able to change its shape to account for skewed data. Fig. 5 presents two different distributions that passed the chi-square test. The first plot shows the sample distribution of ${ }^{248} \mathrm{Cm}$ masses for the W1414WO assembly design, and the second plot shows the sample distribution of ${ }^{241} \mathrm{Am}$ masses for the W1414W assembly design. If a sample distribution qualifies for the first path, the SFD estimate is tested against the Weibull distribution that is fitted to the sample at a significance level of $95 \%$. If the estimate is not ruled out from belonging to the distribution, then it is given a score of " 1 " for that particular assembly design. If the estimate is rejected by the test, then it is given a score of "0." For example, Fig. 5 also plots the SFD estimates for the respective nuclides in the Ginna spent fuel. In plot (a), the estimate passed the test; whereas in (b), the estimate failed the test.

If a sample distribution does not qualify for the first path, a simpler elimination procedure is employed. If the SFD estimate falls anywhere between the lowest sample point and the highest, it is assumed that the estimate could represent the distribution and is given a score of " 1 ." If the estimate is smaller or larger than all of the sample points, then it is ruled out as a representative value for that distribution and is given a score of " 0. "

The second step in the calculation combines the scores for the assembly designs into one score for the individual reactor. This is completed using Eq. (4), which is a weighted average of the design scores. 


$$
\text { Individual Reactor Score }=\sum_{j=1}^{N}\left(\frac{m_{j}}{M}\right)(\text { Assembly Design Score })_{j}
$$

Here, $j$ represents a specific assembly design, $N$ represents the total number of assembly designs used by the assembly class, $m_{j}$ represents the number of assemblies used for design $j$ up until 2004, and $M$ represents the total number of assemblies used by that assembly class up until 2004. Using the example of Ginna again, here $N$ would be six designs, $M$ would be 5448 assemblies, and $m_{j}$ would be the values listed in the last column of Table 2 .

The final step in the calculation of the AR of each nuclide in an assembly class is to average together the individual reactor scores in that class. This is formulized in Eq. (5).

$$
A R=\frac{1}{R} \sum_{k=1}^{R} \text { Individual Reactor } \text { Score }_{k}
$$

Here, $R$ is the number of reactors in the assembly class, and $k$ represents a specific reactor. It should be noted that the AR is a score associated with each nuclide in the SFD. This analysis was completed using only the estimates for spent fuel upon removal from the core, but it is assumed that the AR values calculated here are also valid for the older spent fuel since decay paths are standardized.

\section{Results}

Using the AR methodology, overall scores were compiled for the nuclides contained in the SFD for each of the assembly classes. The results are plotted in histograms: Fig. 6 presents the group assembly classes, and Fig. 7 presents the four individual assembly classes. 


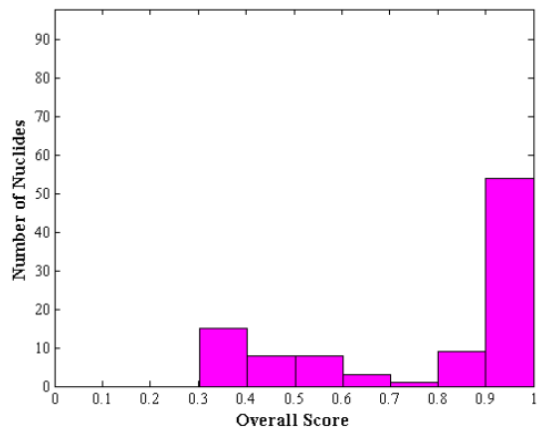

(a)

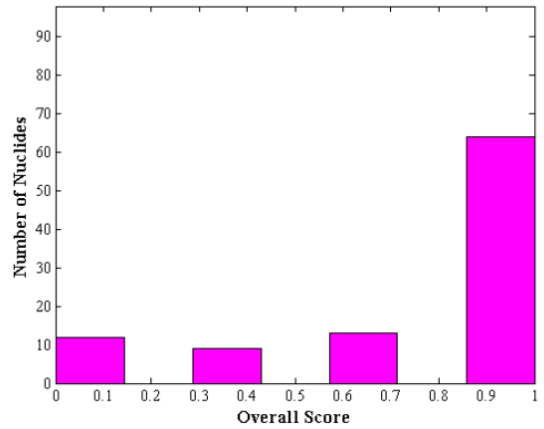

(d)

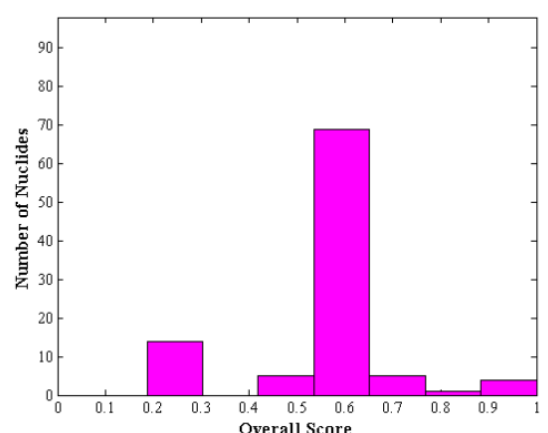

(g)

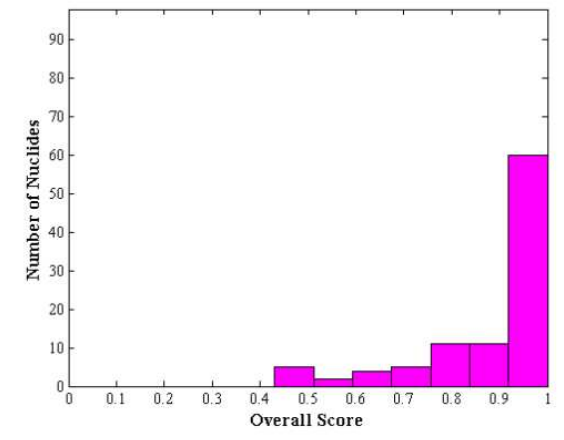

(b)

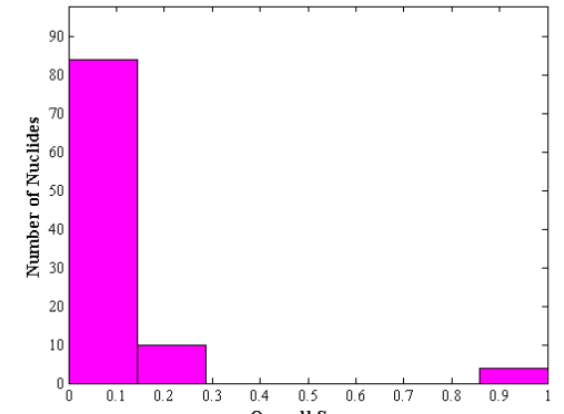

(e)

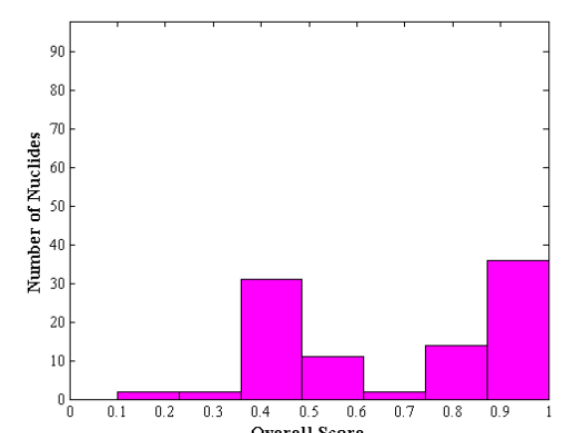

(h)

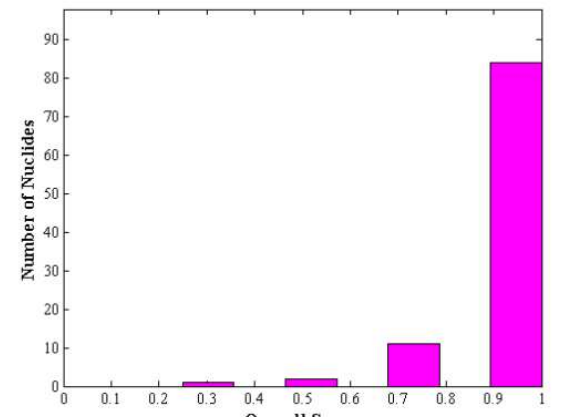

(c)

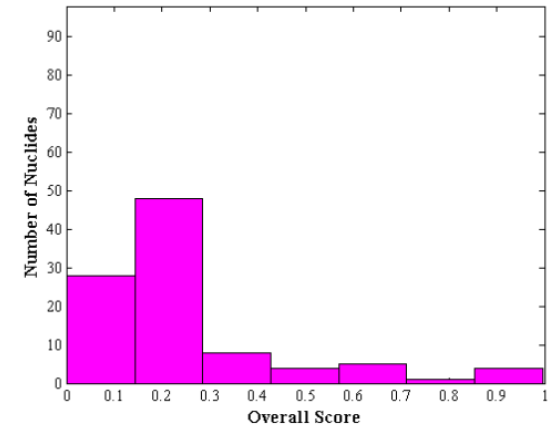

(f)

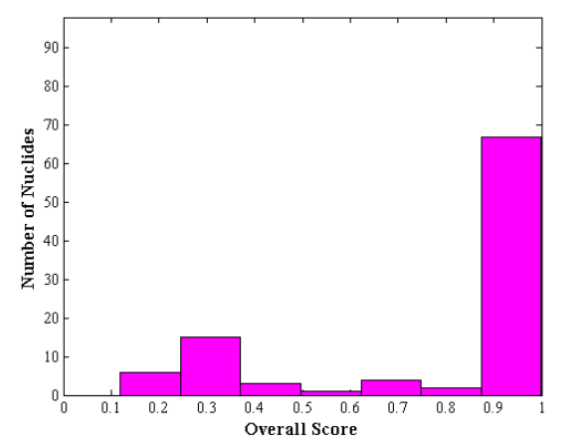

(i)

Fig. 6. Overall AR scores for the 98 database nuclides within the (a) B\&W 15x15, (b) CE 14x14, (c) CE 16x16, (d) CE 16x16 System 80, (e) GE BWR 2,3, (f) GE BWR 4,6, (g) W 14x14, (h) W 15x15, and (i) W 17x17 assembly classes. 


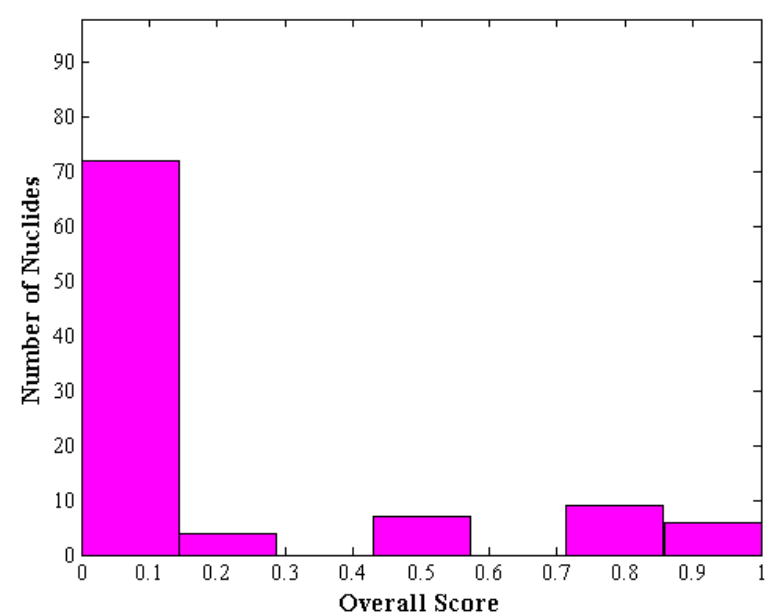

(a)

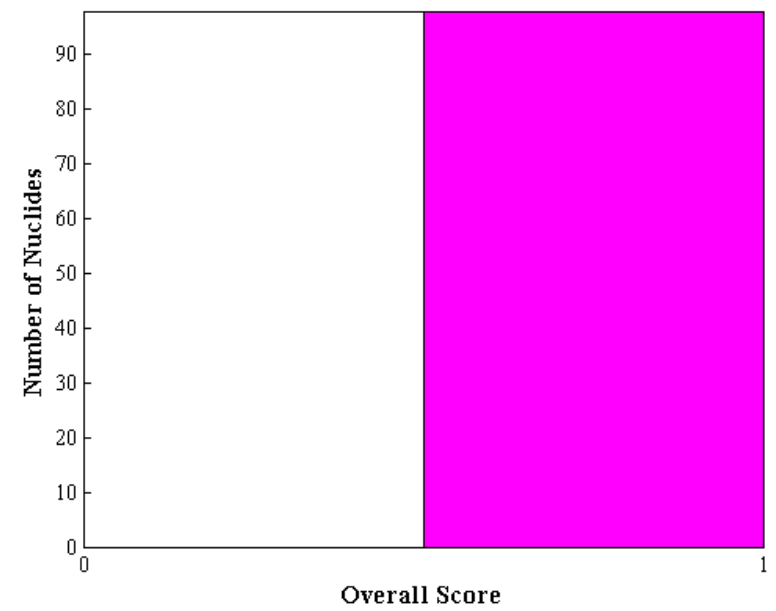

(c)

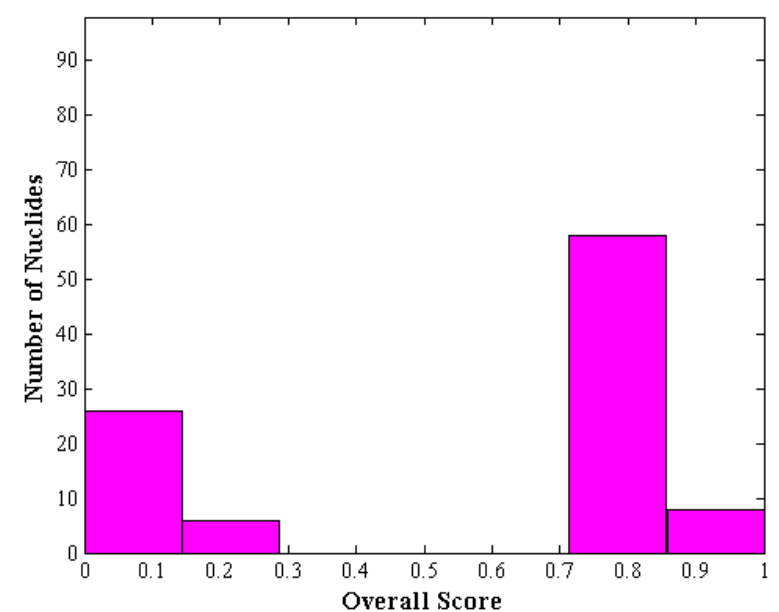

(b)

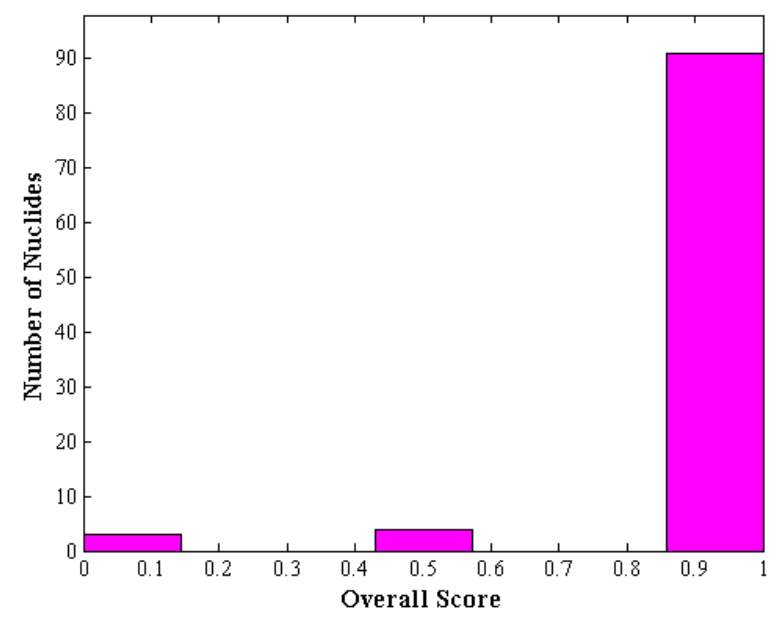

(d)

Fig. 7. ARs for the SFD within the (a) Fort Calhoun, (b) Palisades, (c) Saint Lucie Unit 2, and (d) South Texas individual assembly classes. 
A number of observations can be made about Fig. 6 and Fig. 7. Data for PWR assembly classes tend to have higher AR values than data for BWR assembly classes. This is expected because PWRs use higher enrichments than BWRs and therefore would be much closer to the assumption of 4.0 wt.\% enrichment. For a similar reason, data for older assembly classes tend to have lower ARs than data for newer assembly classes. Other interesting details can be pulled out:

- The data for the Fort Calhoun and Palisades individual assembly classes have lower ARs than the CE 16x16 assembly class data, even though both reactors use the CE 16x16 reactor design.

- The Saint Lucie Unit 2 assembly class data have higher ARs than the CE 14x14 assembly class data, and the unit uses the CE $14 \times 14$ reactor design.

- The South Texas assembly class data have higher ARs than the W 17x17 assembly class data, even though both of the South Texas units use the W 17x17 reactor design.

- The CE 16x16 assembly class data have the highest ARs in general.

- The data for the GE BWR and the Fort Calhoun assembly classes have the lowest ARs. These observations emphasize the usefulness of the methodology for analyzing the database. The spread of the distributions for the individual assembly classes are much smaller than the spread for the group assembly classes, echoed by the more extreme AR values in comparison with their counterpart group assembly class. Another benefit of the method is the ability to weight the design scores based on their historical frequency and variation. The mass estimates for the CE 16x16 assembly class have the highest AR values because this particular class has only used one assembly design in the past. Therefore, the 4080 historical assemblies that populate this design have a large distribution spread, making the database assumptions better able to represent this particular class. For assembly classes that have used more than one assembly design, the AR scores reflect how representative the estimates are of each of them. The more popular designs have larger 
distributions of enrichment and initial uranium content that make it more likely that the SFD estimates will be able to represent those particular designs. The special project assemblies with populations below 10 do not significantly affect the AR values but are still accounted for in the calculation. This methodology combines all of the individual design test results into one neat number for the entire assembly class. This reiterates the interpretation of an AR: it is approximately the fraction of historical assemblies that can be represented by the SFD estimates.

The numerical values of the results presented in Fig. 6 and Fig. 7can be found in the Appendix. It is left up to the reader to choose the line separating an acceptable AR from an unacceptable one. A SFD estimate with an AR of 0.50 may or may not be acceptable depending on the situation. For a general study, a mass estimate that is representative of $50 \%$ of the spent fuel assemblies from a particular reactor may be sufficient given the broad variation in assembly designs over the years. For a study needing precision, such as for a non-proliferation analysis, an AR of 0.50 may not be good enough. In that case, using one estimate to represent the entire historical population may not be sufficient.

Fig. 8 presents a closer look at four nuclides: ${ }^{99} \mathrm{Tc},{ }^{235} \mathrm{U},{ }^{239} \mathrm{Pu}$, and ${ }^{241} \mathrm{Am}$. The AR values for these nuclides are presented for each of the PWR group assembly classes. The BWR and the individual assembly class AR values are not shown due to the extreme tendencies highlighted in Fig. 6 and Fig. 7. The patterns of the AR scores for ${ }^{99} \mathrm{Tc}$ and ${ }^{235} \mathrm{U}$ are similar-if the assumptions produced a representative mass estimate of ${ }^{235} \mathrm{U}$, then it makes sense that the score for ${ }^{99} \mathrm{Tc}$ would be similarly representative given its direct yield from fission. However, the scores for the higher nuclides ${ }^{239} \mathrm{Pu}$ and ${ }^{241} \mathrm{Am}$ tend to be lower than ${ }^{235 \mathrm{U}}$, which reflects the accumulated bias from parent nuclides. Between the assembly classes, the CE classes tend to have higher AR values given the broad historical distributions of a small number of designs compared to the more numerous designs in the other classes. There are deviations from these patterns when the mass estimates are 
right at the boundary of rejection, where a random sample can send the test either way, but these relationships hold in general.

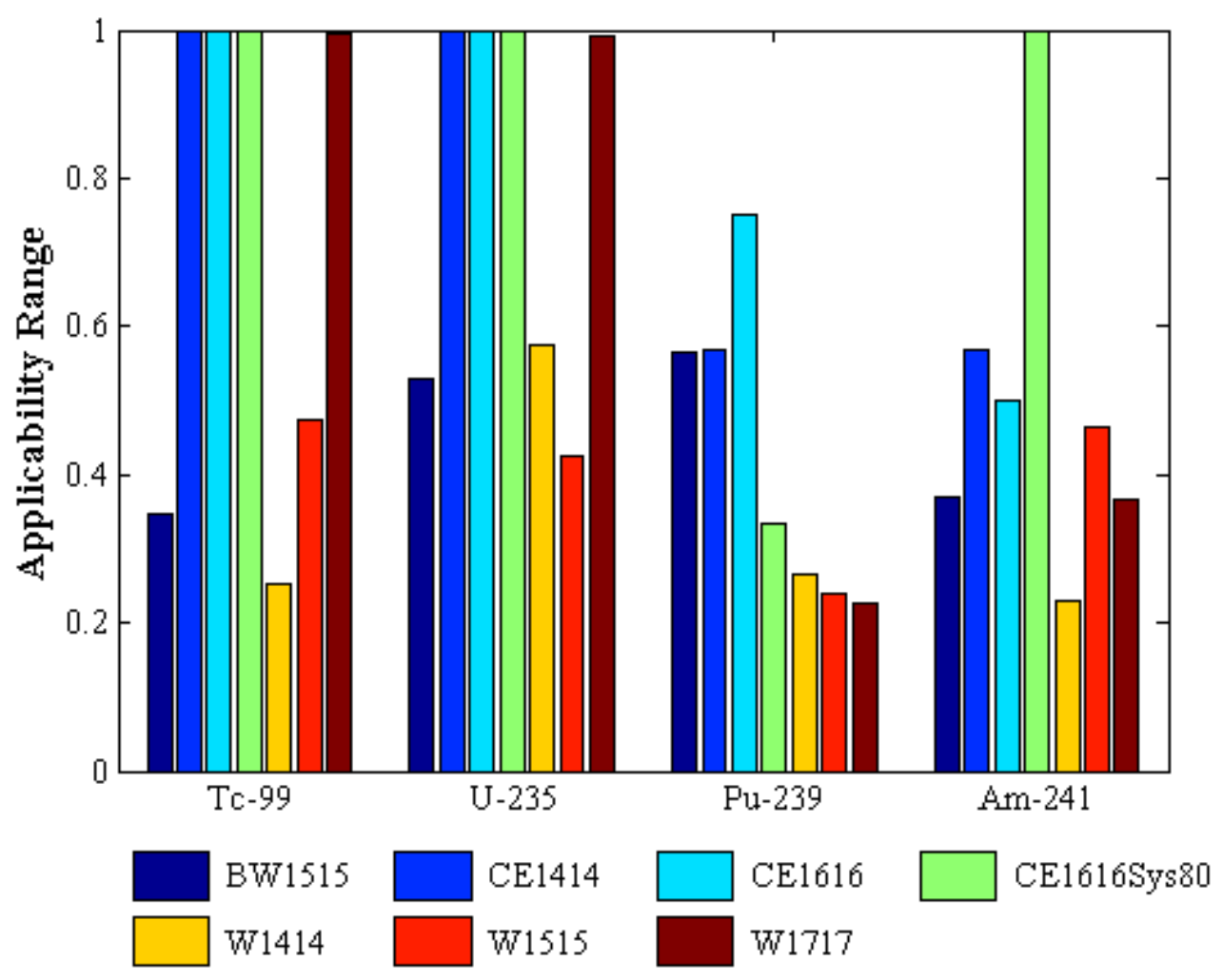

Fig. 8. AR values for ${ }^{99} \mathrm{Tc},{ }^{235} \mathrm{U},{ }^{239} \mathrm{Pu}$, and ${ }^{241} \mathrm{Am}$ for each of the PWR group assembly classes.

To further demonstrate the application of AR values, consider the practical example of the heat load of an assembly after five years of decay. Fig. 9 presents this metric for each of the group assembly classes as determined by the SFD estimates. The height of the bar denotes the total heat load, and the contributions from the five hottest nuclides are stacked in the bar. The BWR assemblies have a much smaller heat load than the PWR assemblies, which makes sense given their smaller size and lower power density. The five hottest nuclides are identical for all of the assemblies after five years, although the order of contribution is different between the PWR and 
BWR assembly types $\left({ }^{134} \mathrm{Cs},{ }^{244} \mathrm{Cm},{ }^{238} \mathrm{Pu},{ }^{137} \mathrm{Cs}\right.$, and ${ }^{90} \mathrm{Sr}$ for the former, and ${ }^{134} \mathrm{Cs},{ }^{137} \mathrm{Cs},{ }^{90} \mathrm{Sr},{ }^{238} \mathrm{Pu}$, and ${ }^{244} \mathrm{Cm}$ for the latter).

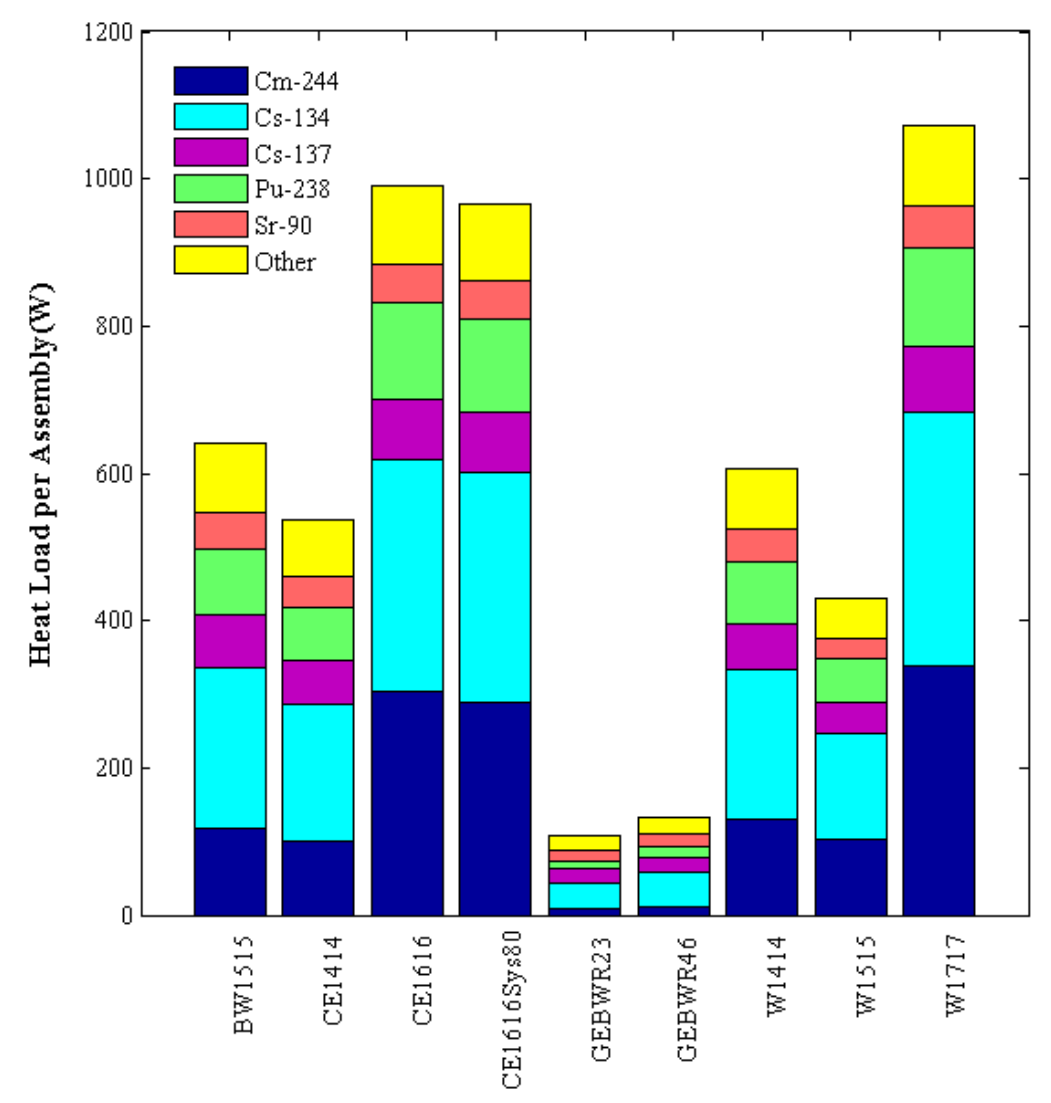

Fig. 9. Heat load of an average assembly five years after removal from the reactor core, calculated using SFD mass estimates.

While the information presented in Fig. 9 is useful and seems reasonable in aggregate, the simplifying assumptions used to create the SFD throw the individual results into question. To explore this idea further, Fig. 10 compares the composition of the heat load for the group with the highest AR scores against the group with the lowest AR scores, the CE 16x16 and the GE BWR 2,3 assembly classes respectively. The five hottest nuclides in the average CE $16 x 16$ assembly all have an AR score of 1.0, so these numbers are representative of all CE $16 \times 16$ assemblies in relation to the 
two variables studied. Only two of the five hottest nuclides even have a non-zero AR value for the GE BWR 2,3 average assembly. At best, the heat contribution from the ${ }^{90} \mathrm{Sr}$ represents about $19 \%$, or 4893, historical GE BWR 2,3 assemblies. Even though the relationships shown in Fig. 9 seem reasonable, the individual mass estimates and their derived quantities have varying levels of applicability. This is an important consideration to avoid making broad blanket statements regarding heat load and to instead specify that a statement is only representative of a certain fraction of historical fuel assemblies. Moreover, the AR values indicate where the SFD needs to be improved, since the data for three significant nuclides do not represent any historical GE BWR 2,3 assembly, which affects not only the individual estimates but also the aggregate information.

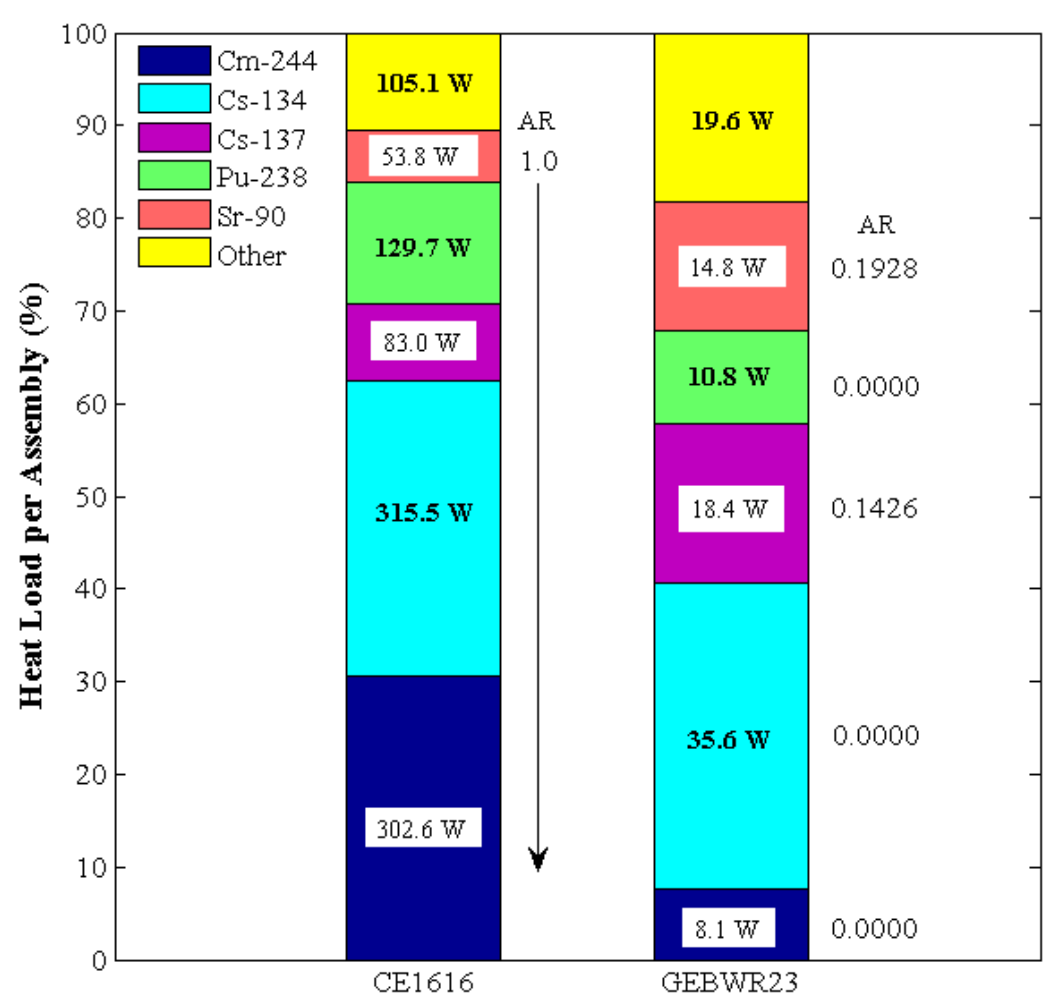

Fig. 10. Composition of the heat load from an average assembly belonging to the specified group assembly class after five years of decay. The heat was estimated based on SFD data. The magnitude for each nuclide is indicated on the stacked bar, and the associated AR value is shown to the right. 


\section{Conclusions}

The analysis presented in this paper centered on the idea of an "applicability range" evaluation, which quantifies how representative one estimate is in relation to the known historical variation of its input variables. The AR methodology was developed and applied to the estimates contained in the Spent Fuel Database.

The AR methodology consists of two major steps: the implementation of a sampling and randomization scheme and the calculation of the AR scores. This research used the Latin Hypercube Sampling method to pick sample enrichment and initial uranium values from triangular distributions. The distributions were formed based on public information detailing the average, minimum, and maximum values for all of the assembly designs used by the nuclear industry up until 2004. The sample values for the two input variables were randomly paired together, and the original reactor models were rerun using the new sample points. The SFD mass estimates were then evaluated against the new sample distributions to determine if the estimate could represent the sample. A score of " 1 " was assigned if the estimate passed the test and " 0 " if it failed. The scores for an individual reactor were found using a weighted average of the assembly design scores, and the final AR scores for an assembly class were found by averaging the individual reactor scores in its group.

In applying the AR methodology to the SFD estimates, the results showed that the estimates in some assembly classes are more representative than estimates in other assembly classes. The estimates for newer, PWR assembly classes had much higher AR values than estimates for older or BWR assembly classes. The AR values for the estimates in the individual assembly classes tended to group together either close to "0" or close to "1," which makes sense given the small sample sizes for these reactors.

The clusters of AR values close to "0" for both BWR assembly classes and for the Fort Calhoun individual assembly class suggests that future work should focus on making the estimates 
in these classes more representative of their respective historical spent fuel assemblies. While the assumed values of the initial uranium content were close to the historical mean for these assemblies, the assumption of $4.0 \mathrm{wt} \%$ enrichment was much higher the maximum historical enrichment values for the majority of the designs. This indicates that the methodology used to generate the database should be amended to allow for the value of uranium enrichment to vary from reactor to reactor.

The AR methodology can be extended to other applications beyond analyzing the SFD. Any study using one representative value in place of a variable that has a history of large variations can use this method to determine the fraction of the variable's population that it represents. Many times, input values are chosen in academic studies for convenience, and it is important to understand how that might impact the applicability of the study to real-world systems. It is not always possible to perform a complete uncertainty analysis. In complex systems, such as the historical reactor fleet, there are numerous factors that might contribute to the uncertainty of a mass estimate—shutdown times, boron coolant concentrations, and more-and these cannot always be quantified or modeled. In the example of the SFD, the wide variations in the historical assembly designs not only indicate uncertainties in enrichment values and initial uranium content values but also an evolution of the technology. The AR methodology provides an alternative metric that can be used to describe how representative an estimate is of its historical counterparts.

\section{For the Editor and Reviewers}

General Note: This word document includes plots that were formatted as "tiff." I am also uploading "eps" versions of these figures with this submission to provide more scalable pictures for you. I am leaving the tiff versions in this document so that you know where to place the eps versions. This comment corresponds to Figs. 2 through 7.

Footnotes: 
1 JMP was created by John Sall and originally stood for "John's Macintosh Program" (Shipp and Lafler, 2012). Today, it is pronounced, "jump."

\section{Acknowledgements}

The authors are grateful to Michael Leimon for his help in writing a Python script to automate the task of writing the thousands of input decks needed for this analysis. This material is based upon work done with the support of a Department of Energy NEUP project 11-0942 on transmutation of fission products in mixed radiation fields. It was completed with the support of the National Science Foundation under Grant No. 1252521.

\section{References}

2012. JMP Pro, 10.0.0 ed. SAS Institute Inc., Cary, NC.

EIA, 1995. Spent Nuclear Fuel Discharges from U.S. Reactors 1993. Technical Report, Energy Information Administration, SR/CNEAF/95-01, Washington, D.C.

Gauld, I.C., Bowman, S.M., Horwedel, J.E., 2009. ORIGEN-ARP: Automatic Rapid Processing for Spent Fuel Depletion, Decay, and Source Term Analysis. ORNL/TM-2005/39, Oak Ridge, TN, p. D1.1.1 to D1.3.4.

Kotz, S., Dorp, J.R.v., 2004. Beyond Beta: Other Continuous Families of Distributions with Bounded Support and Applications. World Scientific Publishing Co. Pte. Ltd., Singapore.

Minasny, B., 2004. Latin Hypercube Sampling, MATLAB Central File Exchange, updated on 18 November 2004. <http://www.mathworks.com/matlabcentral/fileexchange/4352-latinhypercube-sampling> (accessed 24 June 2014).

NRC, 2011a. Approved Applications for Power Uprates. $<$ http://www.nrc.gov/reactors/operating/licensing/power-uprates/status-powerapps/approved-applications.html> (accessed Dec. 23, 2011).

NRC, 2011b. Information Digest, 2011-2012 (NUREG - 1350, Volume 23). Technical Report, Nuclear Regulatory Commission.

NRC, 2011c. Operating Nuclear Power Reactors (by Location or Name). $<$ http://www.nrc.gov/infofinder/reactor/\#listAlpha > (accessed November 28, 2011).

Shipp, C.E., Lafler, K.P., 2012. Proficiency in JMP Visualization, SAS Global Forum 2012, Orlando, FL. 
Vose, D., 2000. How Monte Carlo simulation works, Risk Analysis: A quantitative guide, 2nd ed. John Wiley \& Sons, LTD, Chichester, England, pp. 59 - 62.

Wagner, J.C., Peterson, J.L., Mueller, D.E., Gehin, J.C., Worrall, A., Taiwo, T., Nutt, M., Williamson, M.A., Todosow, M., Wigeland, R., Halsey, W.G., Omberg, R.P., Swift, P.N., Carter, J.T., 2012. Categorization of Used Nuclear Fuel Inventory in Support of a Comprehensive National Nuclear Fuel Cycle Strategy. Technical Report, ORNL/TM-2012/308, Oak Ridge, TN.

Yancey, K., Tsvetkov, P.V., 2014. Quantification of U.S. spent fuel inventories in nuclear waste management. Annals of Nuclear Energy 72, 277-285. 


\section{Appendix}

Table 3

AR scores for the SFD nuclides, by PWR assembly class. $\left({ }^{239} \mathrm{Am}\right.$ to $\left.{ }^{250} \mathrm{Cm}\right)$

\begin{tabular}{|l|l|l|l|l|l|l|l|}
\hline Nuclide & BW15x15 & CE14x14 & CE16x16 & $\begin{array}{l}\text { CE16x16 } \\
\text { Sys80 }\end{array}$ & W14x14 & W15x15 & W17x17 \\
\hline Am-239 & 0.9185 & 1.0 & 1.0 & 0.6667 & 0.5826 & 0.4859 & 0.7246 \\
\hline Am-240 & 0.9185 & 1.0 & 1.0 & 0.6667 & 0.5826 & 0.4859 & 0.6875 \\
\hline Am-241 & 0.3687 & 0.5677 & 0.5000 & 1.0 & 0.2295 & 0.4651 & 0.3669 \\
\hline Am-242 & 0.9185 & 1.0 & 1.0 & 0.6667 & 0.5826 & 0.5419 & 0.7034 \\
\hline Am-242m & 0.3687 & 0.7389 & 0.7500 & 1.0 & 0.2053 & 0.4370 & 0.3478 \\
\hline Am-243 & 0.9185 & 1.0 & 1.0 & 0.3333 & 0.5738 & 0.8740 & 0.9855 \\
\hline Am-244 & 0.9185 & 1.0 & 1.0 & 1.0 & 0.5738 & 0.8743 & 0.9865 \\
\hline Am-244m & 1.0 & 1.0 & 1.0 & 1.0 & 1.0 & 1.0 & 1.0 \\
\hline Am-245 & 0.9185 & 1.0 & 1.0 & 1.0 & 0.5738 & 0.8743 & 0.9635 \\
\hline Am-246 & 0.9185 & 1.0 & 1.0 & 1.0 & 0.5738 & 0.8743 & 0.9447 \\
\hline Bk-249 & 0.9208 & 1.0 & 0.7500 & 1.0 & 0.5738 & 0.8740 & 0.9240 \\
\hline Bk-250 & 0.9208 & 1.0 & 0.7500 & 1.0 & 0.5738 & 0.8743 & 0.9332 \\
\hline Bk-251 & 0.9208 & 0.8289 & 1.0 & 1.0 & 0.6175 & 0.8743 & 0.9650 \\
\hline Cd-113m & 0.9277 & 1.0 & 1.0 & 1.0 & 0.6178 & 0.8930 & 0.9967 \\
\hline Cf-249 & 0.9231 & 1.0 & 1.0 & 1.0 & 0.5738 & 0.8740 & 0.9429 \\
\hline Cf-250 & 0.9208 & 1.0 & 1.0 & 1.0 & 0.5738 & 0.8740 & 0.9278 \\
\hline Cf-251 & 0.9208 & 0.8289 & 1.0 & 1.0 & 0.5093 & 0.8740 & 0.9726 \\
\hline Cf-252 & 0.9208 & 0.8289 & 1.0 & 1.0 & 0.5738 & 0.7620 & 0.9798 \\
\hline Cf-253 & 0.9208 & 1.0 & 1.0 & 1.0 & 0.6175 & 0.8183 & 0.9817 \\
\hline Cf-254 & 0.9208 & 1.0 & 1.0 & 1.0 & 0.6175 & 0.8180 & 0.9815 \\
\hline Cf-255 & 0.9208 & 1.0 & 1.0 & 1.0 & 0.5738 & 0.8743 & 0.9804 \\
\hline Cm-241 & 0.9185 & 1.0 & 1.0 & 0.3333 & 0.5738 & 0.7277 & 0.9812 \\
\hline Cm-242 & 0.9185 & 1.0 & 1.0 & 1.0 & 0.5738 & 0.7554 & 0.9401 \\
\hline Cm-243 & 0.9185 & 1.0 & 1.0 & 1.0 & 0.5738 & 0.7769 & 0.9816 \\
\hline Cm-244 & 0.9208 & 1.0 & 1.0 & 1.0 & 0.5738 & 0.8740 & 0.9818 \\
\hline Cm-245 & 0.9208 & 1.0 & 1.0 & 1.0 & 0.5738 & 0.8180 & 0.9791 \\
\hline Cm-246 & 0.9208 & 0.8289 & 1.0 & 0.6667 & 0.5738 & 0.8180 & 0.9747 \\
\hline Cm-247 & 0.9208 & 1.0 & 1.0 & 1.0 & 0.5738 & 0.8740 & 0.9695 \\
\hline Cm-248 & 0.9208 & 1.0 & 1.0 & 1.0 & 0.5738 & 0.8740 & 0.9484 \\
\hline Cm-249 & 0.9208 & 1.0 & 1.0 & 1.0 & 0.5738 & 0.8743 & 0.9012 \\
\hline Cm-250 & 0.9208 & 0.8289 & 1.0 & 0.6667 & 0.6175 & 0.8740 & 0.9597 \\
\hline & & & & & & & \\
\hline
\end{tabular}


Table 3

Continued. $\left({ }^{251} \mathrm{Cm}\right.$ to $\left.{ }^{241} \mathrm{Pu}\right)$

\begin{tabular}{|c|c|c|c|c|c|c|c|}
\hline Nuclide & BW15x15 & CE14x14 & CE16x16 & $\begin{array}{l}\text { CE16x16 } \\
\text { Sys80 }\end{array}$ & W14x14 & W15x15 & W17x17 \\
\hline $\mathrm{Cm}-251$ & 0.9208 & 0.8289 & 1.0 & 0.6667 & 0.6175 & 0.8743 & 0.9527 \\
\hline Cs-134 & 0.9185 & 1.0 & 1.0 & 1.0 & 0.4885 & 0.8109 & 0.7231 \\
\hline Cs-135 & 0.5304 & 1.0 & 1.0 & 1.0 & 0.4448 & 0.4260 & 0.9927 \\
\hline Cs-137 & 0.5342 & 0.9550 & 1.0 & 1.0 & 0.5738 & 0.5940 & 0.9884 \\
\hline Eu-154 & 0.9185 & 1.0 & 1.0 & 0.3333 & 0.5738 & 0.8889 & 0.9812 \\
\hline Eu-155 & 0.9185 & 1.0 & 1.0 & 1.0 & 0.5738 & 0.8883 & 0.9930 \\
\hline $\mathrm{He}-4$ & 0.9276 & 1.0 & 1.0 & 0.6667 & 0.6728 & 0.8370 & 0.9588 \\
\hline $\mathrm{I}-129$ & 0.9231 & 1.0 & 1.0 & 1.0 & 0.5738 & 0.9598 & 0.9965 \\
\hline $\mathrm{Kr}-85$ & 0.3471 & 0.9550 & 1.0 & 1.0 & 0.5738 & 0.4260 & 0.9965 \\
\hline $\mathrm{Nb}-94$ & 0.9208 & 1.0 & 1.0 & 1.0 & 0.5738 & 0.8954 & 0.9965 \\
\hline Np-235 & 0.7113 & 0.8536 & 1.0 & 0.0 & 0.6333 & 0.5117 & 0.1184 \\
\hline Np-236 & 0.8251 & 0.9100 & 1.0 & 1.0 & 0.5738 & 0.5594 & 0.9973 \\
\hline $\mathrm{Np}-236 \mathrm{~m}$ & 0.4957 & 0.6261 & 1.0 & 0.0 & 0.6451 & 0.4409 & 0.2834 \\
\hline Np-237 & 0.8970 & 0.9100 & 1.0 & 1.0 & 0.5738 & 0.4260 & 0.9965 \\
\hline $\mathrm{Np}-238$ & 0.4936 & 0.6261 & 1.0 & 0.0 & 0.6267 & 0.4409 & 0.2834 \\
\hline $\mathrm{Np}-239$ & 0.9185 & 1.0 & 1.0 & 1.0 & 0.5738 & 0.8183 & 0.9965 \\
\hline Np-240 & 0.9185 & 1.0 & 0.7500 & 0.6667 & 0.5738 & 0.7548 & 0.2834 \\
\hline $\mathrm{Np}-240 \mathrm{~m}$ & 0.9208 & 1.0 & 0.7500 & 0.6667 & 0.5738 & 0.8740 & 0.8203 \\
\hline $\mathrm{Np}-241$ & 1.0 & 1.0 & 1.0 & 1.0 & 1.0 & 1.0 & 0.8922 \\
\hline $\mathrm{Pa}-231$ & 0.3471 & 1.0 & 1.0 & 1.0 & 0.5738 & 0.4260 & 0.9651 \\
\hline $\mathrm{Pa}-232$ & 0.3471 & 1.0 & 1.0 & 1.0 & 0.5738 & 0.4260 & 1.0 \\
\hline $\mathrm{Pa}-233$ & 0.8970 & 0.9100 & 1.0 & 1.0 & 0.5738 & 0.4260 & 0.9927 \\
\hline $\mathrm{Pa}-234$ & 0.4199 & 0.6261 & 1.0 & 0.0 & 0.6451 & 0.4409 & 0.9932 \\
\hline Pa-234m & 0.5985 & 0.7389 & 0.5000 & 1.0 & 0.2975 & 0.4075 & 0.9965 \\
\hline $\mathrm{Pa}-235$ & 1.0 & 1.0 & 1.0 & 1.0 & 1.0 & 1.0 & 0.2832 \\
\hline Pd-107 & 0.9231 & 1.0 & 1.0 & 1.0 & 0.5738 & 0.8740 & 0.3734 \\
\hline Pm-147 & 0.5304 & 1.0 & 1.0 & 1.0 & 0.1869 & 0.4745 & 1.0 \\
\hline $\mathrm{Pu}-236$ & 0.6214 & 0.9100 & 1.0 & 0.0 & 0.7362 & 0.4746 & 0.9927 \\
\hline Pu-237 & 0.3687 & 0.4303 & 1.0 & 0.0 & 0.2490 & 0.4655 & 0.9927 \\
\hline $\mathrm{Pu}-238$ & 0.6596 & 0.7725 & 1.0 & 0.0 & 0.7230 & 0.2526 & 0.1657 \\
\hline $\mathrm{Pu}-239$ & 0.5666 & 0.5677 & 0.7500 & 0.3333 & 0.2664 & 0.2380 & 0.2252 \\
\hline $\mathrm{Pu}-240$ & 0.4603 & 0.7389 & 0.2500 & 0.6667 & 0.1869 & 0.3948 & 0.1887 \\
\hline $\mathrm{Pu}-241$ & 0.8269 & 0.7389 & 1.0 & 1.0 & 0.6178 & 0.6190 & 0.3274 \\
\hline
\end{tabular}


Table 3

Continued. ( ${ }^{242} \mathrm{Pu}$ to ${ }^{93} \mathrm{Zr}$ )

\begin{tabular}{|c|c|c|c|c|c|c|c|}
\hline Nuclide & BW15x15 & CE14x14 & CE16x16 & $\begin{array}{l}\text { CE16x16 } \\
\text { Sys80 }\end{array}$ & W14x14 & W15x15 & W17x17 \\
\hline $\mathrm{Pu}-242$ & 0.9185 & 1.0 & 1.0 & 1.0 & 0.5738 & 0.8954 & 0.3003 \\
\hline $\mathrm{Pu}-243$ & 0.9185 & 0.8289 & 1.0 & 1.0 & 0.5738 & 0.8183 & 0.4918 \\
\hline $\mathrm{Pu}-244$ & 0.9185 & 0.8289 & 0.7500 & 0.6667 & 0.5738 & 0.8740 & 0.9589 \\
\hline $\mathrm{Pu}-245$ & 0.9185 & 1.0 & 1.0 & 1.0 & 0.5738 & 0.8743 & 0.9255 \\
\hline $\mathrm{Pu}-246$ & 0.9185 & 1.0 & 1.0 & 1.0 & 0.5738 & 0.8743 & 0.9651 \\
\hline $\mathrm{Ru}-106$ & 0.9185 & 1.0 & 1.0 & 1.0 & 0.5738 & 0.8743 & 0.9635 \\
\hline Sb-125 & 0.9231 & 1.0 & 1.0 & 1.0 & 0.5738 & 0.8743 & 0.9447 \\
\hline Se-79 & 0.3471 & 1.0 & 1.0 & 1.0 & 0.5738 & 0.4260 & 0.9661 \\
\hline Sm-151 & 0.9007 & 0.9100 & 1.0 & 0.6667 & 0.4549 & 0.7883 & 0.9931 \\
\hline Sn-126 & 0.9231 & 1.0 & 1.0 & 1.0 & 0.5738 & 0.9169 & 0.9927 \\
\hline Sr-90 & 0.3471 & 0.9550 & 1.0 & 1.0 & 0.5738 & 0.4260 & 0.3842 \\
\hline Tc-99 & 0.3471 & 1.0 & 1.0 & 1.0 & 0.2513 & 0.4745 & 0.9935 \\
\hline Th-226 & 0.4603 & 0.4866 & 1.0 & 0.3333 & 0.2306 & 0.4789 & 0.9965 \\
\hline Th-227 & 0.4645 & 0.8536 & 1.0 & 0.0 & 0.4724 & 0.5465 & 0.9927 \\
\hline Th-228 & 0.3927 & 0.6578 & 0.7500 & 0.0 & 0.6527 & 0.5496 & 0.2701 \\
\hline Th-229 & 0.3687 & 0.9436 & 0.7500 & 0.3333 & 0.1869 & 0.5658 & 0.2871 \\
\hline Th-230 & 0.8970 & 0.9100 & 1.0 & 1.0 & 0.5738 & 0.4260 & 0.2418 \\
\hline Th-231 & 0.3471 & 1.0 & 1.0 & 1.0 & 0.5738 & 0.4260 & 0.3306 \\
\hline Th-232 & 0.8970 & 1.0 & 1.0 & 1.0 & 0.5738 & 0.4260 & 0.9951 \\
\hline Th-233 & 0.8213 & 0.9100 & 1.0 & 1.0 & 0.6178 & 0.4581 & 0.9892 \\
\hline Th-234 & 0.5029 & 0.9100 & 1.0 & 0.3333 & 0.2975 & 0.1003 & 0.9965 \\
\hline U-230 & 0.4603 & 0.4866 & 1.0 & 0.3333 & 0.2306 & 0.4789 & 0.5340 \\
\hline U-231 & 0.4603 & 0.4866 & 1.0 & 0.0 & 0.2306 & 0.4863 & 0.2969 \\
\hline U-232 & 0.6526 & 0.8289 & 1.0 & 0.0 & 0.7875 & 0.4136 & 0.2628 \\
\hline U-233 & 0.3471 & 1.0 & 1.0 & 1.0 & 0.5738 & 0.4260 & 0.2600 \\
\hline U-234 & 0.3033 & 0.4550 & 0.7500 & 0.0 & 0.6828 & 0.4880 & 0.2428 \\
\hline U-235 & 0.5304 & 1.0 & 1.0 & 1.0 & 0.5738 & 0.4260 & 0.9927 \\
\hline U-236 & 0.8970 & 1.0 & 1.0 & 1.0 & 0.5738 & 0.4260 & 0.9931 \\
\hline U-237 & 0.8970 & 0.9100 & 1.0 & 1.0 & 0.5738 & 0.4260 & 0.9627 \\
\hline $\mathrm{U}-238$ & 0.5051 & 0.7389 & 1.0 & 0.3333 & 0.2975 & 0.1103 & 0.3071 \\
\hline U-239 & 0.9185 & 1.0 & 1.0 & 1.0 & 0.5738 & 0.8183 & 0.8318 \\
\hline $\mathrm{U}-240$ & 0.9208 & 0.8289 & 0.7500 & 0.6667 & 0.5738 & 0.8740 & 0.9665 \\
\hline $\mathrm{U}-241$ & 1.0 & 1.0 & 1.0 & 1.0 & 1.0 & 1.0 & 1.0 \\
\hline Zr-93 & 0.3471 & 1.0 & 1.0 & 1.0 & 0.5738 & 0.4260 & 0.9959 \\
\hline
\end{tabular}




\section{Table 4}

AR scores for the SFD nuclides, by BWR and individual assembly classes. $\left({ }^{239} \mathrm{Am}\right.$ to $\left.{ }^{250} \mathrm{Cm}\right)$

\begin{tabular}{|l|l|l|l|l|l|l|}
\hline Nuclide & GE BWR 2,3 & GE BWR 4,6 & $\begin{array}{l}\text { Fort } \\
\text { Calhoun }\end{array}$ & Palisades & $\begin{array}{l}\text { St. Lucie } \\
\text { unit 2 }\end{array}$ & South Texas \\
\hline Am-239 & 0.0570 & 0.1733 & 0.0 & 0.7475 & 1.0 & 1.0 \\
\hline Am-240 & 0.0397 & 0.1700 & 0.0 & 0.7475 & 1.0 & 1.0 \\
\hline Am-241 & 0.0325 & 0.2499 & 0.0 & 0.7475 & 1.0 & 0.5000 \\
\hline Am-242 & 0.0713 & 0.1733 & 0.0 & 0.7475 & 1.0 & 1.0 \\
\hline Am-242m & 0.0086 & 0.2416 & 0.4982 & 0.7475 & 1.0 & 1.0 \\
\hline Am-243 & 0.0181 & 0.2852 & 0.0 & 0.7475 & 1.0 & 1.0 \\
\hline Am-244 & 0.0 & 0.2550 & 0.0 & 0.7475 & 1.0 & 1.0 \\
\hline Am-244m & 1.0 & 0.9959 & 1.0 & 1.0 & 1.0 & 1.0 \\
\hline Am-245 & 0.0 & 0.2615 & 0.0 & 0.7475 & 1.0 & 1.0 \\
\hline Am-246 & 0.0 & 0.2395 & 0.0 & 0.7475 & 1.0 & 1.0 \\
\hline Bk-249 & 0.0 & 0.2678 & 0.0 & 0.7475 & 1.0 & 1.0 \\
\hline Bk-250 & 0.0 & 0.2534 & 0.0 & 0.7475 & 1.0 & 1.0 \\
\hline Bk-251 & 0.0 & 0.2494 & 0.0 & 0.7475 & 1.0 & 1.0 \\
\hline Cd-113m & 0.2378 & 0.5964 & 0.7271 & 0.7475 & 1.0 & 1.0 \\
\hline Cf-249 & 0.0 & 0.2672 & 0.0 & 0.7475 & 1.0 & 1.0 \\
\hline Cf-250 & 0.0 & 0.2568 & 0.0 & 0.7475 & 1.0 & 1.0 \\
\hline Cf-251 & 0.0 & 0.2553 & 0.0 & 0.7475 & 1.0 & 1.0 \\
\hline Cf-252 & 0.0 & 0.2729 & 0.0 & 0.7475 & 1.0 & 1.0 \\
\hline Cf-253 & 0.0 & 0.2775 & 0.0 & 0.7475 & 1.0 & 1.0 \\
\hline Cf-254 & 0.0 & 0.2800 & 0.0 & 0.7475 & 1.0 & 1.0 \\
\hline Cf-255 & 0.0 & 0.2843 & 0.0 & 0.7475 & 1.0 & 1.0 \\
\hline Cm-241 & 0.0296 & 0.1944 & 0.0 & 0.7475 & 1.0 & 1.0 \\
\hline Cm-242 & 0.0967 & 0.2110 & 0.0 & 0.7475 & 1.0 & 1.0 \\
\hline Cm-243 & 0.0773 & 0.2124 & 0.0 & 0.7475 & 1.0 & 1.0 \\
\hline Cm-244 & 0.0 & 0.2885 & 0.0 & 0.7475 & 1.0 & 1.0 \\
\hline Cm-245 & 0.0 & 0.2816 & 0.0 & 0.7475 & 1.0 & 1.0 \\
\hline Cm-246 & 0.0 & 0.2807 & 0.0 & 0.7475 & 1.0 & 1.0 \\
\hline Cm-247 & 0.0 & 0.2668 & 0.0 & 0.7475 & 1.0 & 1.0 \\
\hline Cm-248 & 0.0 & 0.2636 & 0.0 & 0.7475 & 1.0 & 1.0 \\
\hline Cm-249 & 0.0 & 0.2620 & 0.0 & 0.7475 & 1.0 & 1.0 \\
\hline Cm-250 & 0.0 & 0.2415 & 0.0 & 0.7475 & 1.0 & 1.0 \\
\hline & & & & & & \\
\hline
\end{tabular}




\section{Table 4}

Continued. $\left({ }^{251} \mathrm{Cm}\right.$ to $\left.{ }^{241} \mathrm{Pu}\right)$

\begin{tabular}{|c|c|c|c|c|c|c|}
\hline Nuclide & GE BWR 2,3 & GE BWR 4,6 & $\begin{array}{l}\text { Fort } \\
\text { Calhoun }\end{array}$ & Palisades & $\begin{array}{l}\text { St. Lucie } \\
\text { unit } 2\end{array}$ & South Texas \\
\hline $\mathrm{Cm}-251$ & 0.0 & 0.2585 & 0.0 & 0.7475 & 1.0 & 1.0 \\
\hline Cs-134 & 0.0 & 0.1917 & 0.0 & 0.0 & 1.0 & 1.0 \\
\hline Cs-135 & 0.0 & 0.0056 & 0.0 & 0.0 & 1.0 & 1.0 \\
\hline Cs-137 & 0.1426 & 0.0549 & 0.0 & 0.0 & 1.0 & 1.0 \\
\hline Eu-154 & 0.0296 & 0.2162 & 0.0 & 0.7475 & 1.0 & 1.0 \\
\hline Eu-155 & 0.0019 & 0.2387 & 0.0 & 0.7475 & 1.0 & 1.0 \\
\hline $\mathrm{He}-4$ & 0.0917 & 0.5914 & 0.4982 & 0.7475 & 1.0 & 1.0 \\
\hline $\mathrm{I}-129$ & 0.1262 & 0.4208 & 0.4982 & 0.7475 & 1.0 & 1.0 \\
\hline Kr-85 & 0.1936 & 0.0636 & 0.0 & 0.0 & 1.0 & 1.0 \\
\hline $\mathrm{Nb}-94$ & 0.1182 & 0.2756 & 0.4982 & 0.7475 & 1.0 & 1.0 \\
\hline $\mathrm{Np}-235$ & 0.0 & 0.0592 & 0.0 & 0.2525 & 1.0 & 1.0 \\
\hline $\mathrm{Np}-236$ & 0.0711 & 0.7516 & 0.7712 & 0.7475 & 1.0 & 1.0 \\
\hline $\mathrm{Np}-236 \mathrm{~m}$ & 0.0 & 0.5513 & 0.7712 & 1.0 & 1.0 & 1.0 \\
\hline Np-237 & 0.2386 & 0.5927 & 1.0 & 0.7475 & 1.0 & 1.0 \\
\hline $\mathrm{Np}-238$ & 0.0 & 0.5590 & 0.7712 & 1.0 & 1.0 & 1.0 \\
\hline $\mathrm{Np}-239$ & 0.0477 & 0.1999 & 0.0 & 0.7475 & 1.0 & 1.0 \\
\hline $\mathrm{Np}-240$ & 0.0 & 0.2035 & 0.0 & 0.7475 & 1.0 & 1.0 \\
\hline $\mathrm{Np}-240 \mathrm{~m}$ & 0.0 & 0.2887 & 0.0 & 0.7475 & 1.0 & 1.0 \\
\hline $\mathrm{Np}-241$ & 1.0 & 0.9959 & 1.0 & 1.0 & 1.0 & 1.0 \\
\hline Pa-231 & 0.0 & 0.0058 & 0.0 & 0.0 & 1.0 & 1.0 \\
\hline $\mathrm{Pa}-232$ & 0.0859 & 0.0470 & 0.0 & 0.0 & 1.0 & 1.0 \\
\hline $\mathrm{Pa}-233$ & 0.2008 & 0.6319 & 1.0 & 0.7475 & 1.0 & 1.0 \\
\hline $\mathrm{Pa}-234$ & 0.0 & 0.5485 & 0.7712 & 1.0 & 1.0 & 1.0 \\
\hline $\mathrm{Pa}-234 \mathrm{~m}$ & 0.0 & 0.1318 & 0.0 & 0.2525 & 1.0 & 1.0 \\
\hline $\mathrm{Pa}-235$ & 1.0 & 0.9959 & 1.0 & 1.0 & 1.0 & 1.0 \\
\hline Pd-107 & 0.0936 & 0.2802 & 0.4982 & 0.7475 & 1.0 & 1.0 \\
\hline Pm-147 & 0.0 & 0.0047 & 0.0 & 0.0 & 1.0 & 1.0 \\
\hline $\mathrm{Pu}-236$ & 0.0 & 0.1933 & 0.2729 & 0.2525 & 1.0 & 0.0 \\
\hline $\mathrm{Pu}-237$ & 0.0 & 0.0287 & 0.0 & 0.0 & 1.0 & 0.5000 \\
\hline Pu-238 & 0.0 & 0.0426 & 0.0 & 0.0 & 1.0 & 0.5000 \\
\hline Pu-239 & 0.0672 & 0.0996 & 0.0 & 0.2525 & 1.0 & 1.0 \\
\hline $\mathrm{Pu}-240$ & 0.0608 & 0.3134 & 0.0 & 0.7475 & 1.0 & 1.0 \\
\hline $\mathrm{Pu}-241$ & 0.0033 & 0.1999 & 0.7271 & 0.7475 & 1.0 & 1.0 \\
\hline
\end{tabular}




\section{Table 4}

Continued. (242Pu to ${ }^{93} \mathrm{Zr}$ )

\begin{tabular}{|c|c|c|c|c|c|c|}
\hline Nuclide & GE BWR 2,3 & GE BWR 4,6 & $\begin{array}{l}\text { Fort } \\
\text { Calhoun }\end{array}$ & Palisades & $\begin{array}{l}\text { St. Lucie } \\
\text { unit } 2\end{array}$ & South Texas \\
\hline $\mathrm{Pu}-242$ & 0.0591 & 0.2723 & 0.0 & 0.7475 & 1.0 & 1.0 \\
\hline $\mathrm{Pu}-243$ & 0.0 & 0.2206 & 0.0 & 0.7475 & 1.0 & 1.0 \\
\hline $\mathrm{Pu}-244$ & 0.0 & 0.2887 & 0.0 & 0.7475 & 1.0 & 1.0 \\
\hline $\mathrm{Pu}-245$ & 0.0 & 0.2590 & 0.0 & 0.7475 & 1.0 & 1.0 \\
\hline $\mathrm{Pu}-246$ & 0.0 & 0.2395 & 0.0 & 0.7475 & 1.0 & 1.0 \\
\hline Ru-106 & 0.0591 & 0.2411 & 0.0 & 0.7475 & 1.0 & 1.0 \\
\hline Sb-125 & 0.1040 & 0.2796 & 0.4982 & 0.7475 & 1.0 & 1.0 \\
\hline Se-79 & 0.1176 & 0.0058 & 0.0 & 0.0 & 1.0 & 1.0 \\
\hline Sm-151 & 0.0 & $7.125 \mathrm{E}-4$ & 0.0 & 0.0 & 1.0 & 1.0 \\
\hline Sn-126 & 0.1095 & 0.3592 & 0.4982 & 0.7475 & 1.0 & 1.0 \\
\hline Sr-90 & 0.1928 & 0.0590 & 0.0 & 0.0 & 1.0 & 1.0 \\
\hline Tc-99 & 0.0 & 0.0056 & 0.0 & 0.0 & 1.0 & 1.0 \\
\hline Th-226 & 0.0 & 0.0460 & 0.0 & 0.0 & 1.0 & 1.0 \\
\hline Th-227 & 0.1250 & 0.0109 & 0.7712 & 0.7475 & 1.0 & 0.0 \\
\hline Th-228 & 0.0397 & 0.2693 & 0.0 & 0.0 & 1.0 & 1.0 \\
\hline Th-229 & 0.0 & 0.1818 & 0.0 & 0.0 & 1.0 & 1.0 \\
\hline Th-230 & 0.0803 & 0.1015 & 0.2729 & 0.0 & 1.0 & 1.0 \\
\hline Th-231 & 0.0430 & 0.0058 & 0.0 & 0.0 & 1.0 & 1.0 \\
\hline Th-232 & 0.1928 & 0.0656 & 0.0 & 0.0 & 1.0 & 1.0 \\
\hline Th-233 & 0.2080 & 0.6870 & 0.7712 & 0.7475 & 1.0 & 1.0 \\
\hline Th-234 & 0.0019 & 0.1129 & 0.0 & 0.2525 & 1.0 & 1.0 \\
\hline $\mathrm{U}-230$ & 0.0 & 0.0460 & 0.0 & 0.0 & 1.0 & 1.0 \\
\hline $\mathrm{U}-231$ & 0.0 & 0.0441 & 0.0 & 0.0 & 1.0 & 1.0 \\
\hline $\mathrm{U}-232$ & 0.0 & 0.2548 & 0.2729 & 0.0 & 1.0 & 0.5000 \\
\hline $\mathrm{U}-233$ & 0.0 & 0.0058 & 0.0 & 0.0 & 1.0 & 1.0 \\
\hline $\mathrm{U}-234$ & 0.0578 & 0.2170 & 0.2729 & 1.0 & 1.0 & 0.0 \\
\hline $\mathrm{U}-235$ & 0.0 & 0.0058 & 0.0 & 0.0 & 1.0 & 1.0 \\
\hline $\mathrm{U}-236$ & 0.1598 & 0.0836 & 0.0 & 0.0 & 1.0 & 1.0 \\
\hline $\mathrm{U}-237$ & 0.1732 & 0.5149 & 0.7712 & 0.7475 & 1.0 & 1.0 \\
\hline $\mathrm{U}-238$ & 0.0 & 0.1157 & 0.0 & 0.2525 & 1.0 & 1.0 \\
\hline $\mathrm{U}-239$ & 0.0477 & 0.1999 & 0.0 & 0.7475 & 1.0 & 1.0 \\
\hline $\mathrm{U}-240$ & 0.0 & 0.2874 & 0.0 & 0.7475 & 1.0 & 1.0 \\
\hline $\mathrm{U}-241$ & 1.0 & 0.9959 & 1.0 & 1.0 & 1.0 & 1.0 \\
\hline Zr-93 & 0.1754 & 0.0424 & 0.0 & 0.0 & 1.0 & 1.0 \\
\hline
\end{tabular}

